\title{
Comprehensive Evaluation of Paraffin-HDPE Shape stabilized PCM with Hybrid Carbon Nano-additives
}

\author{
Y. Qu ${ }^{\mathrm{a}, *}$, S. Wang ${ }^{\mathrm{a}}$, Y. Tian ${ }^{\mathrm{b}}$, D. Zhou ${ }^{\mathrm{c}}$ \\ ${ }^{a}$ College of New Energy, China University of Petroleum, Qingdao 266580, China \\ ${ }^{\mathrm{b}}$ Institute of Energy and Sustainable Development, School of Engineering and Sustainable Development, \\ De Montfort University, Leicestershire, LE1 9BH, UK \\ ${ }^{\mathrm{c}}$ Centre for Renewable Energy Systems Technologies (CREST), \\ Wolfson School of Mechanical, Electrical and Manufacturing Engineering, \\ Loughborough University, Leicestershire, LE11 3TU, UK \\ *Corresponding author, Email: yanqu@upc.edu.cn, Tel: (+86) 532-86983482
}

\begin{abstract}
:
Thermal energy storage using phase change materials (PCMs) is of great interests in many fields, especially in solar thermal applications. To overcome the leakage problem caused by phase change and the low thermal conductivities of most PCMs, especially paraffin, the current study prepared and tested two Paraffin-HDPE-based composites by adding two hybrid Carbon Nano-additives (CNs) fillers: Expanded Graphite-Multi-walled Carbon Nanotube (EG-MWCNT) and Expanded Graphite-Carbon Nanofiber (EG-CNF). A comprehensive evaluation method was first proposed based on the Efficacy Coefficient Method (ECM) to assess the thermal performance of Paraffin-HDPE shape stabilized PCM (SSPCM). Seven individual indexes, including phase change temperature, latent heat, thermal conductivity, leakage rate, specific heat of both solid and liquid phase, and heat storage/heat release rates, were measured and applied to obtain the overall efficacy coefficients of the prepared SSPCM composites. The results showed that in all studied composites, n-octadecane-HDPE/EG-MWCNT composite exhibited the best comprehensive thermal performance with an optimal mass ratio of EG and MWCNT being 4:1.
\end{abstract}

Please cite as:

Y. Qu, S. Wang, Y. Tian, D. Zhou, "Comprehensive Evaluation of Paraffin-HDPE Shape Stabilized PCM with Hybrid Carbon Nano-Additives", Applied Thermal Engineering 163, 2019, 114404, https://doi.org/10.1016/j.applthermaleng.2019.114404 
Keyword: Shape stabilized PCM (SSPCM); hybrid CNs filler; comprehensive evaluation; overall efficacy coefficient.

\section{Highlights}

- Effects of EG-MWCNT and EG-CNF on Paraffin-HDPE SSPCMs were investigated.

- A method for assessing the thermal performance of the SSPCMs was proposed.

- Overall efficacy coefficients of the SSPCMs were obtained by seven indexes.

- Optimal mass ratios of hybrid CNs fillers were revealed for the studied SSPCMs. 


\begin{tabular}{|c|c|c|}
\hline \multicolumn{3}{|c|}{ Nomenclature } \\
\hline$A$ & integral area & $\mathrm{m}^{2}$ \\
\hline$B$ & convective heat transfer area of the test tube & $\mathrm{m}^{2}$ \\
\hline$B i$ & Biot number & \\
\hline$c_{p}$ & specific heat & $\mathrm{kJ} /(\mathrm{kg} \cdot \mathrm{K})$ \\
\hline$d_{i}$ & efficacy coefficient & \\
\hline$D_{i}$ & total efficacy coefficient & \\
\hline$h$ & natural convection heat transfer coefficient & $\mathrm{W} /\left(\mathrm{m}^{2} \cdot \mathrm{K}\right)$ \\
\hline$H_{m}$ & latent heat & $\mathrm{kJ} / \mathrm{kg}$ \\
\hline$k$ & thermal conductivity & $\mathrm{W} /(\mathrm{m} \cdot \mathrm{K})$ \\
\hline$m$ & mass & $\mathrm{kg}$ \\
\hline$m_{0}$ & initial mass & $\mathrm{kg}$ \\
\hline$m_{n}$ & heated mass & $\mathrm{kg}$ \\
\hline$R$ & radius of test tube & $\mathrm{mm}$ \\
\hline$R_{m}$ & radius of phase transition & $\mathrm{mm}$ \\
\hline$t$ & time & $\mathrm{s}$ \\
\hline$T_{0}$ & uniform temperature & ${ }^{\circ} \mathrm{C}$ \\
\hline$T_{\infty}$ & ambient temperature & ${ }^{\circ} \mathrm{C}$ \\
\hline$T_{m}$ & phase change temperature & ${ }^{\circ} \mathrm{C}$ \\
\hline$T_{r}$ & reference temperature & ${ }^{\circ} \mathrm{C}$ \\
\hline$X_{h i}$ & highest level or the set value of evaluation index & \\
\hline$X_{s i}$ & worst level or the set value of evaluation index & \\
\hline $\bar{X}_{i}$ & mean value & \\
\hline \multicolumn{3}{|l|}{ Acronyms } \\
\hline$C F$ & carbon fibers & \\
\hline$C N$ & carbon nano-additives & \\
\hline$C N F$ & carbon nanofibers & \\
\hline CNT & carbon nanotubes & \\
\hline$E C M$ & efficacy coefficient method & \\
\hline$E G$ & expanded graphite & \\
\hline$E V A$ & ethylene vinyl acetate & \\
\hline GNP & graphene nanoplates & \\
\hline$H D P E$ & high density polyethylene & \\
\hline$L R$ & leakage rate & $\%$ \\
\hline$M F R$ & melt mass flow rate & \\
\hline$M W C N T$ & multi-walled carbon nanotubes & \\
\hline$O M T$ & organophilic montmorillonite & \\
\hline$S B S$ & styrene-butadiene-styrene & \\
\hline$S S P C M$ & Shape stabilized phase change material & \\
\hline TCE & thermal conductivity enhancer & \\
\hline \multicolumn{3}{|c|}{ Greek letter } \\
\hline$\delta$ & deviation & \\
\hline$\rho$ & density & $\mathrm{g} / \mathrm{cm}^{3}$ \\
\hline$\sigma_{i}$ & standard deviation & \\
\hline$v_{i}$ & coefficient of variation & \\
\hline$\omega_{i}$ & weight factor & \\
\hline
\end{tabular}




\begin{tabular}{|ll|}
\hline Subscripts & freezing \\
$f$ & liquid \\
$l$ & PCM \\
$p$ & solid \\
$s$ & test tube \\
$t$ & water \\
$w$ & \\
\hline
\end{tabular}

\section{Introduction}

Thermal energy storage using phase change materials (PCMs) is of great interests in many fields such as solar energy systems, energy efficient buildings, central air-conditioning systems and floor radiant heating [1]. Incorporating paraffin-based PCMs into the traditional building structures can passively use solar energy to reduce the temperature swing and keep the thermal comfort in building spaces, in turn to increase the energy efficiency in new and refurbished buildings [2].

However, paraffin has low thermal conductivity (with an average of $0.2 \mathrm{~W} /(\mathrm{m} \cdot \mathrm{K})$ ) which reduces the heat transfer rate during the melting and solidification cycles. In addition, paraffin suffers from leakage during the solid-liquid transition. Therefore, the studies on effective encapsulation and thermal conductivity enhancement of paraffin are of great significance. Considerable efforts have been devoted to enhance the thermal conductivity of PCM with the approaches including the introduction of metal structures in various forms such as fins [3], honeycomb [4], and the addition of different high thermal conductive additives to the PCM, such as carbon nano-additives (CNs) [5]-[7] and metal nano-particles [8]-[9], in which, CNs are considered as the most promising additives. Until now, most previous researches have focused on the thermal conductivity enhancement of PCM by single $\mathrm{CN}$, which were summarized and compared in our previous study [10].

Shape stabilized PCM (SSPCM) is one of the methods currently being used for encapsulating PCMs to solve the problems of leakage and volatilization [11]. Zhu et al. [12] reviewed the studies of thermal dynamic characteristics and thermal performance of buildings integrated with SSPCMs in the recent years (from 2008 to 2018) and they found the building envelope enhanced by SSPCM can significantly narrow indoor temperature fluctuations and reduce energy demands. Zhou and Eames [13] concluded that the percentage of energy saving by using SSPCM in a passive building could be as high as $40 \%$. Inaba and $\mathrm{Tu}[14]$ proposed to fabric a shape stabilized PCM using paraffin and 
high-density polyethylene (HDPE), in which, HDPE occupied 26wt.\%. Zhang et al. [15] manufactured a shape stabilized PCM board by paraffin and HDPE for building applications and found the optimal composition of HDPE of 20wt.\%. Qin et al. [16] found significant leakage of Paraffin-HDPE SSPCMs when the mass fraction of HDPE reduced to lower than $10 \mathrm{wt} . \%$. Summarized from the literature, the lowest mass fraction of HDPE needed in paraffin-HDPE composites could be suggested as 23wt.\% [16], 24wt.\% [18] and 25wt.\% [19] without any paraffin seepage when melted. Inevitably, incorporating HDPE into paraffin can affect the thermal properties of the composite. Table 1 summarized the effects of HDPE content on melting point and latent heat of SSPCMs from literature. Obviously, HDPE had only a little effect on the melting point while influenced latent heat negatively and greatly.

Table 1 Comparison of melting point and latent heat between paraffin and paraffin-

\begin{tabular}{|c|c|c|c|c|c|c|}
\hline \multicolumn{3}{|c|}{ PCMs } & \multicolumn{3}{|c|}{ HDPE/paraffin SSPCMs } & \\
\hline PCM & $\begin{array}{c}T_{m} \\
\left({ }^{\circ} \mathrm{C}\right)\end{array}$ & $\begin{array}{c}H_{m} \\
(\mathrm{~kJ} / \mathrm{kg})\end{array}$ & $\begin{array}{l}\text { HDPE } \\
\text { (wt.\%) }\end{array}$ & $\begin{array}{c}T_{m} \\
\left({ }^{\circ} \mathrm{C}\right)\end{array}$ & $\begin{array}{c}H_{m} \\
(\mathrm{~kJ} / \mathrm{kg})\end{array}$ & Refs. \\
\hline \multirow[t]{12}{*}{ paraffin } & $42-44$ & 192.8 & 0 & 39.8 & 192.8 & [16] \\
\hline & & & 23 & 37.8 & 147.6 & \\
\hline & & & 25 & 37.4 & 143.9 & \\
\hline & & & 30 & 36.6 & 134.6 & \\
\hline & & & 40 & 35.8 & 114.8 & \\
\hline & & & 50 & 34.9 & 95.7 & \\
\hline & $56-58$ & 212.4 & 0 & 56.6 & 212.4 & \\
\hline & & & 23 & 55.7 & 162.2 & \\
\hline & & & 25 & 55.4 & 158.5 & \\
\hline & & & 30 & 54.9 & 146.1 & \\
\hline & & & 40 & 54.4 & 125.1 & \\
\hline & & & 50 & 53.8 & 103.8 & \\
\hline \multirow[t]{14}{*}{ paraffin } & $48-50$ & 228.32 & 0 & 49.43 & 228.32 & [18] \\
\hline & & & 24 & 44.32 & 179.63 & \\
\hline & & & 27 & 43.89 & 174.51 & \\
\hline & & & 30 & 43.24 & 171.1 & \\
\hline & & & 35 & 42.82 & 163.74 & \\
\hline & & & 40 & 41.11 & 150.12 & \\
\hline & & & 50 & 38.80 & 138.44 & \\
\hline & $63-65$ & 256.64 & 0 & 64.48 & 256.64 & \\
\hline & & & 24 & 61.66 & 198.14 & \\
\hline & & & 27 & 61.28 & 195.91 & \\
\hline & & & 30 & 60.93 & 191.43 & \\
\hline & & & 35 & 60.02 & 188.73 & \\
\hline & & & 40 & 59.21 & 180.18 & \\
\hline & & & 50 & 58.14 & 162.64 & \\
\hline paraffin & - & 198.95 & 25 & - & 157.04 & [19] \\
\hline \multirow[t]{3}{*}{ paraffin } & 20 & 119.66 & 30 & 20.6 & 87.43 & [15] \\
\hline & $60-62$ & 147.8 & 20 & 60 & 137.9 & \\
\hline & & & 25 & 60 & 130.8 & \\
\hline paraffin & $60-62$ & 200 & $10-30$ & - & $130-175$ & [16] \\
\hline paraffin & 54.2 & 164 & 26 & 54.3 & 121 & Error! \\
\hline
\end{tabular}


The paraffin-HDPE SSPCMs still have the low thermal conductivity problems as the thermal conductivity of HDPE is only in a range of 0.45 to $0.52 \mathrm{~W} /(\mathrm{m} \cdot \mathrm{K})$. The addition of CNs can enhance the thermal conductivity and further improve the stabilization of the SSPCMs. A few researches explored to use hybrid $\mathrm{CN}$ fillers and discussed their synergistic effect on the thermal conductivity enhancement of SSPCM, such as EG-Multiwalled Carbon Nano-tube (EG-MWCNT) and EG-CNF fillers [10], EG/Carbon Fiber (CF) [20], expanded graphite platelets (EGP)/MWCNT fillers [21].

Previous researches focused on single factor evaluation of the SSPCMs, but rarely studied the comprehensive performance of SSPCMs. In this study, the comprehensive performance of n-octadecane-HDPE SSPCMs with two kinds of hybrid CNs fillers, EGMWCNT and EG-CNF, were experimentally investigated to develop the superior paraffin-based SSPCMs. As the optimal mass ratio between paraffin, HDPE and CNs in the composite needs further investigation, the Efficacy Coefficient Method (ECM) [22] was firstly proposed to assess the comprehensive performance of SSPCM/CNs, in which, seven parameters were used as the indexes, including latent heat, melting point, specific heat, heat storage/heat release rate, the heat conduction properties characterized by thermal conductivity, and the stability characterized by leakage rate. The optimal mass ratio of paraffin, HDPE and hybrid conductive fillers was obtained from the overall efficacy coefficient.

\section{Experimental}

\subsection{Materials}

The specifications and suppliers of the materials required are listed in Table 2. Paraffin, n-octadecane, with a melting point of $28{ }^{\circ} \mathrm{C}$ was selected as the PCM and the HDPE was used as the basic shaping supporter. EG, MWCNT and CNF, were applied as the enhancers to compare their abilities for thermal conductivity enhancement.

Table 2 Specifications and suppliers of materials required for the experiment

\begin{tabular}{lllll}
\hline Materials & $\begin{array}{l}\rho \\
\left(\mathrm{g} / \mathrm{cm}^{3}\right)\end{array}$ & $\begin{array}{l}k \\
(\mathrm{~W} /(\mathrm{m} \cdot \mathrm{K}))\end{array}$ & Features & Supplier \\
\hline \multirow{3}{*}{ n-octadecane } & & & Purity: $98 \%$ & Sinopharm Chemical \\
& 0.7768 & 0.25 & $\begin{array}{l}T_{m}: 28^{\circ} \mathrm{C} \\
H_{m}: 243.5 \mathrm{~kJ} / \mathrm{kg}\end{array}$ & Reagent Co. Ltd
\end{tabular}




\begin{tabular}{|c|c|c|c|c|}
\hline HDPE & 0.94 & 0.4 & $\begin{array}{l}\text { Purity: } 98 \% \\
T_{m}: 130^{\circ} \mathrm{C} \\
\text { MFR: } 2.5 \mathrm{~g} / \mathrm{min}\end{array}$ & $\begin{array}{l}\text { China Petroleum \& } \\
\text { Chemical Co. Ltd }\end{array}$ \\
\hline EG & 0.035 & 3000 & $\begin{array}{l}\text { Purity: } 98 \% \\
\text { Granularity: } 75 \mu \mathrm{m} \\
\text { Expansion ratio: } 350 \mathrm{ml} / \mathrm{g}\end{array}$ & $\begin{array}{l}\text { Qingdao Hengrunda } \\
\text { Graphene Co. Ltd }\end{array}$ \\
\hline MWCNT & 0.094 & 1950 & $\begin{array}{l}\text { Purity: } 98 \% \\
\text { External diameter: }<8 \mathrm{~nm} \\
\text { Length: } 10-20 \mu \mathrm{m}\end{array}$ & $\begin{array}{l}\text { Chengdu Organic } \\
\text { Chemical Co. Ltd }\end{array}$ \\
\hline $\mathrm{CNF}$ & 0.035 & 1150 & $\begin{array}{l}\text { Purity: } 90 \% \\
\text { Diameter: } 200-600 \mathrm{~nm} \\
\text { Length: } 5-50 \mu \mathrm{m}\end{array}$ & $\begin{array}{l}\text { Suzhou Tanfeng } \\
\text { Graphene Technology } \\
\text { Co. Ltd. }\end{array}$ \\
\hline
\end{tabular}

\subsection{Sample preparation}

Figure 1 shows the general preparation process of the SSPCM samples, n-octadecaneHDPE, n-octadecane-HDPE/EG-MWCNT and n-octadecane-HDPE/EG-CNF. These prepared SSPCMs with different component fractions are shown in Figure 2.

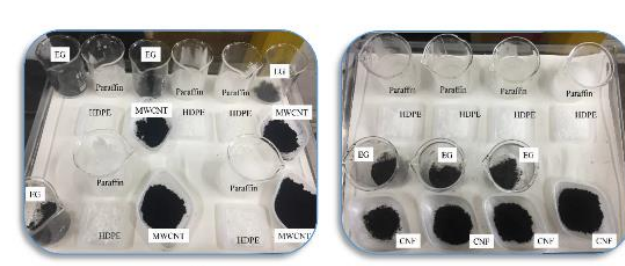

(1) Material weighing

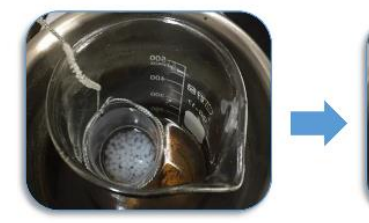

(3) Adding HDPE to Paraffin

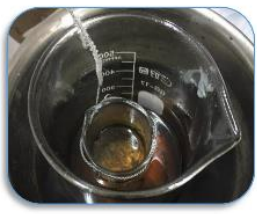

(4) Intensive mixing

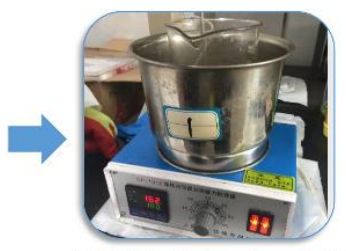

(2) Oil bath heating $180^{\circ} \mathrm{C}$

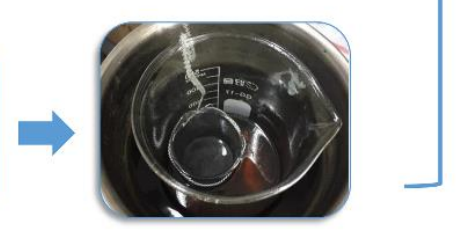

(5) Adding EG-MWCNT or EG-CNF
(6) Moulding and repressing at room temperature

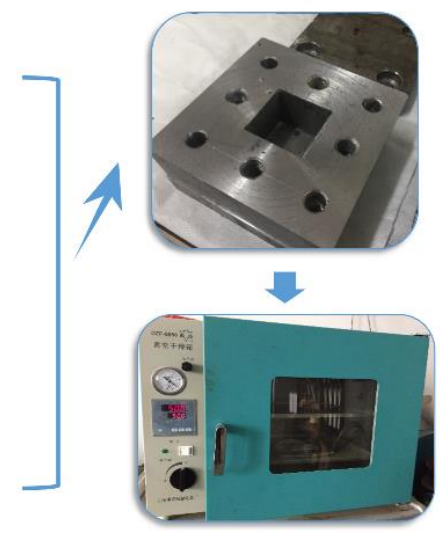

(7) Drying at $50^{\circ} \mathrm{C}$

Fig. 1. Schematic illustration of the preparation of composite PCM
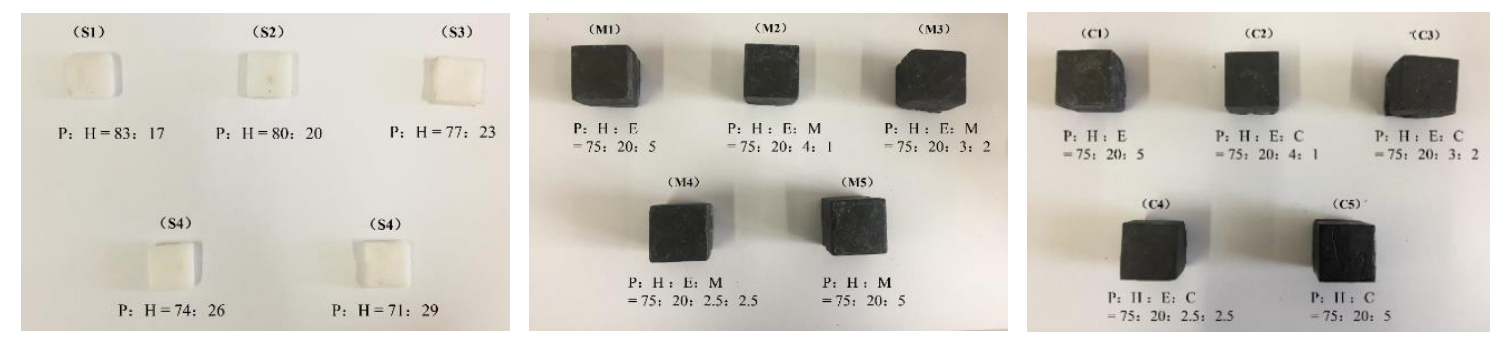

(a) n-octadecane-HDPE; (b) n-octadecane-HDPE/EG-MWCNT; (c) n-octadecane$\mathrm{HDPE} / \mathrm{EG}-\mathrm{CNF}$;

Fig. 2. Photos of composite PCMs

(P: n-octadecane-paraffin, H: HDPE, E: EG, M: MWCNT, C: CNF)

Taking n-octadecane-HDPE SSPCM as an example, the preparation process was as 
follows: 1) a beaker with n-octadecane and HDPE with correct mass fractions was placed in an oil bath with a temperature of $180{ }^{\circ} \mathrm{C}$ until they were fully melted; 2) the liquid mixture was blended by a cantilever agitator at a screw speed of $1500 \mathrm{r} / \mathrm{min}$ for $30 \mathrm{~min}$; 3 ) the liquid mixture was injected into the stainless steel mold and then cooled down to the room temperature; 4) the solid sample was dried in an air-dry oven at a temperature of $50{ }^{\circ} \mathrm{C}$. According to the literature, 20-30wt.\% of HDPE in Paraffin-HDPE SSPCMs can effectively prevent leakage while significant leakage occurs when the percentage is below 10wt.\%. However, inconsistent conclusions were founded for SSPCMs with 10$20 \mathrm{wt} . \%$ of HDPE. Therefore, to assess the optimal proportion of HDPE in the composites, five samples with different mass fractions of HDPE, namely, 17wt.\%, 20wt.\%, 23wt.\%, $26 \mathrm{wt} . \%$ and $29 \mathrm{wt} . \%$ were prepared and tested, with each sample weighing $2 \mathrm{~g}$. The preparation processes of n-octadecane-HDPE/EG-MWCNT and n-octadecaneHDPE/EG-CNF PCM composites were almost the same as described above, except an extra step of adding EG-CNF and EG-MWCNT hybrid fillers into the liquid mixture of n-octadecane-HDPE and blending extra $30 \mathrm{~min}$ before the shape molding and cooling down. The CNs fillers ratios in n-octadecane-based PCMs in literature were mostly in the range of 1-10wt.\%. To make CNs ratio as little as possible under the condition of meeting the requirement of thermal conductivity enhancement, the total mass ratio of CNs (EG and carbon nano-additives) was chosen at 5wt.\%. For n-octadecane-HDPE/EG-MWCNT and n-octadecane-HDPE/EG-CNF PCM composites, each sample weighed $22 \mathrm{~g}$. The compositions of the studied samples were summarized in Table 3.

Table 3 The compositions of the studied samples

\begin{tabular}{ccccccc}
\hline Samples & No. & $\begin{array}{c}\text { n-octadecane } \\
\text { (wt.\%) }\end{array}$ & $\begin{array}{c}\text { HDPE } \\
\text { (wt.\%) }\end{array}$ & $\begin{array}{c}\text { EG } \\
\text { (wt.\%) }\end{array}$ & $\begin{array}{c}\text { MWCNT } \\
\text { (wt.\%) }\end{array}$ & $\begin{array}{c}\text { CNF } \\
\text { (wt.\%) }\end{array}$ \\
\hline \multirow{5}{*}{ n-octadecane } & S1 & 83 & 17 & - & - & - \\
/HDPE & S2 & 80 & 20 & - & - & - \\
& S3 & 77 & 23 & - & - & - \\
& S4 & 74 & 26 & - & - & - \\
& S5 & 71 & 29 & - & - & - \\
\hline n-octadecane & M1 & 75 & 20 & 5 & 0 & - \\
/HDPE & M3 & 75 & 20 & 4 & 1 & - \\
/EG-MWCNT & M4 & 75 & 20 & 3 & 2 & - \\
& M5 & 75 & 20 & 2.5 & 2.5 & - \\
\hline & C1 & 75 & 20 & 0 & 5 & - \\
n-octadecane & C2 & 75 & 20 & 5 & - & 0 \\
/HDPE & $\mathrm{C} 3$ & 75 & 20 & 4 & - & 1 \\
/EG-CNF & $\mathrm{C} 4$ & 75 & 20 & 3 & - & 2 \\
& $\mathrm{C} 5$ & 75 & 20 & 2.5 & - & 2.5 \\
\hline
\end{tabular}




\subsection{Characterization}

\subsubsection{Stability}

The leakage rate $(L R)$ representing the shape stability of SSPCMs was calculated by Eq. (1). During the test, all samples were exposed directly to the environment to weigh without any encapsulation. Firstly, the samples were weighed and marked the mass as mo. Then, they were placed on the filter papers and put in a vacuum oven with a temperature of $50{ }^{\circ} \mathrm{C}$. After an hour, the samples were taken out and weighed as $m_{1}$. Such steps were repeated by $n$ times and the mass of samples was recorded as $m_{n}$. For each component, three samples were prepared and measured, and an average value was taken to calculate the leakage rate of the SSPCM samples.

$$
L R=\frac{m_{0}-m_{n}}{m_{0}} \times 100 \%
$$

\subsubsection{Key thermophysical properties}

The phase change temperature $\left(T_{\mathrm{m}}\right)$, latent heat $\left(H_{\mathrm{m}}\right)$, specific heat $\left(c_{p}\right)$ and thermal conductivity $(k)$ of the composite PCMs can be derived simultaneously through the Thistory method presented by Zhang and Jiang [23]. The schematic diagram of T-history method is shown in Fig. 3. The tubes were filled with the composite PCMs and only one tube was filled with the reference water due to its well-known thermo-physical properties. The tested tubes have a radius of $4 \mathrm{~mm}$ and a length of $200 \mathrm{~mm}$. The composite PCM or water occupied $2 / 3$ volume of each tube, therefore the filling quality was around $8 \sim 10 \mathrm{~g}$ depending on the filling material. The tubes were preheated in a thermostatic water bath to a uniform temperature of $T_{0}=65^{\circ} \mathrm{C}$ which was above the melting temperature of the composite PCM. Then, the test tubes were simultaneously taken out from the water bath and subjected to the ambient temperature $\left(T_{\infty}\right)$ of $25^{\circ} \mathrm{C}$. The curves of thermal history $(T$ vs $t$ ) were recorded during cooling. The T-type thermocouples were placed at the center of the filling materials and the temperatures of measurement points were recorded by Agilent $34972 \mathrm{~A}$ data acquisition instrument with the accuracy within $\pm 0.5{ }^{\circ} \mathrm{C}$. Each test was repeated three times and the measurement was implemented after the samples remained stable. 


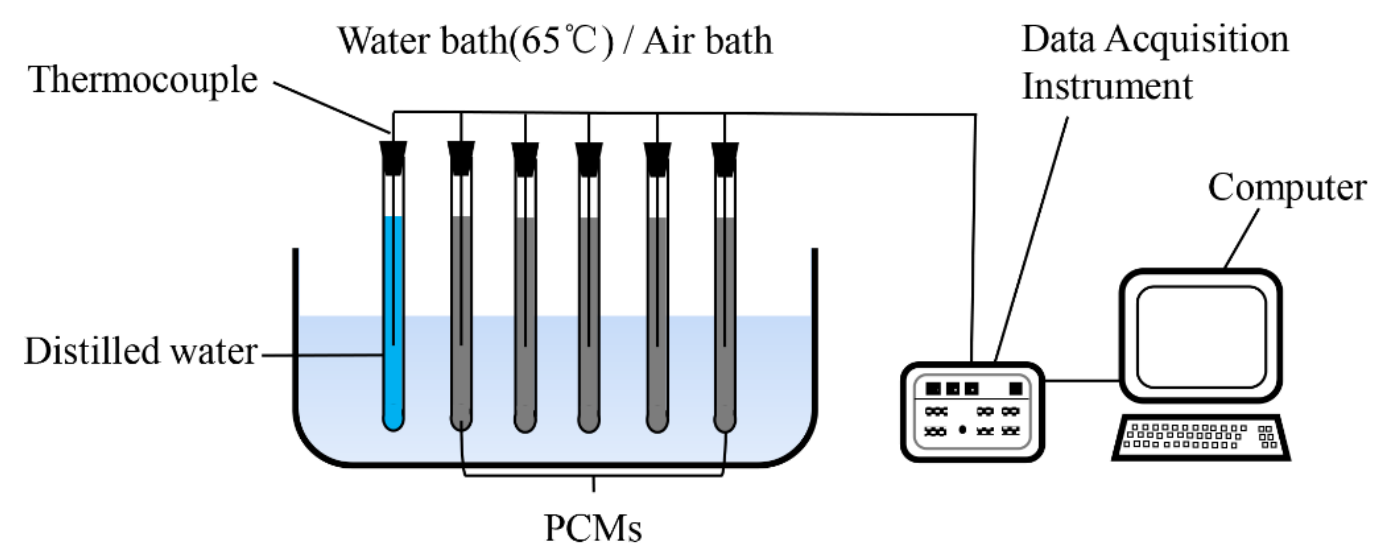

Fig. 3. Schematic diagram of T-history method

The thermal conductivity $(k)$ of organic PCM is generally a bit higher than $0.2 \mathrm{~W} /(\mathrm{m} \cdot \mathrm{K})$ and the natural convective heat transfer coefficient $(h)$ is about $5 \sim 10 \mathrm{~W} /\left(\mathrm{m}^{2} \cdot \mathrm{K}\right)$. Therefore, the Biot number $(B i=h R / 2 k)$ is less than 0.1, indicating that the temperature distribution within the composite PCMs can be considered as uniform and the lumped parameter method can be used for heat transfer analysis.

Taking the $T$ - $t$ curve of n-octadecane in Fig. 4 for example, the curve can be roughly divided into three stages. The first stage $\left(T_{0} \sim T_{m, 1}\right)$ is sensible heat zone $\mathrm{A}_{1}$, in which the sensible heat is released by the PCM and the test tube to the environment. The second stage $\left(T_{m, 1} \sim T_{m, 2}\right)$ is latent heat zone $\mathrm{A}_{2}$, in which the released heat includes the latent heat of PCM due to the phase change and a little sensible heat of the test tube due to a small temperature drop. The third stage $\left(T_{m, 2} \sim T_{r}\right)$ is sensible heat zone $\mathrm{A}_{3}$, where the heat released comprises sensible heat of the solid PCM and the test tube. The energy equations of PCM at $\mathrm{A}_{1}, \mathrm{~A}_{2}, \mathrm{~A}_{3}$ zone are shown in Eqs. (2), (3) and (4), respectively. The energy equations of reference water corresponding to the temperature ranges $T_{0} \sim T_{m, 1}, T_{m, 2} \sim T_{r}$ are shown in Eqs. (5)-(6).

$$
\begin{aligned}
& \left(m_{t} c_{p, t}+m_{p} c_{p, l}\right)\left(T_{0}-T_{\mathrm{m}, 1}\right)=h B A_{1} \\
& m_{p} H_{m}+m_{t} c_{p, t}\left(T_{m, 1}-T_{m, 2}\right)=h B A_{2} \\
& \left(m_{t} c_{p, t}+m_{p} c_{p, s}\right)\left(T_{m, 2}-T_{r}\right)=h B A_{3} \\
& \left(m_{t} c_{p, t}+m_{w} c_{p, w}\right)\left(T_{0}-T_{m, 1}\right)=h B A_{1}^{\prime} \\
& \left(m_{t} c_{p, t}+m_{w} c_{p, w}\right)\left(T_{m, 2}-T_{r}\right)=h B A_{2}^{\prime}
\end{aligned}
$$


where $T_{0}$ is the initial temperature $\left({ }^{\circ} \mathrm{C}\right) ; T_{m, l}$ is the starting temperature of phase change $\left({ }^{\circ} \mathrm{C}\right)$ and $T_{m, 2}$ is the finishing temperature of phase change $\left({ }^{\circ} \mathrm{C}\right) ; T_{r}$ is the reference temperature $\left({ }^{\circ} \mathrm{C}\right)$, which is selected as $21{ }^{\circ} \mathrm{C} ; H_{m}$ is latent heat $(\mathrm{kJ} / \mathrm{kg}) ; h$ is the natural convective heat transfer coefficient of air $\left(\mathrm{W} /\left(\mathrm{m}^{2} \cdot \mathrm{K}\right)\right) ; B$ is the convective heat transfer area of the test tube $\left(\mathrm{m}^{2}\right) ; m_{p}, m_{t}$, and $m_{w}$ are the mass of PCM, test tube and water $(\mathrm{kg})$, respectively; $c_{p, l}, c_{p, s}, c_{p, t}$ and $c_{p, w}$ are the specific heat values $(\mathrm{kJ} /(\mathrm{kg} \cdot \mathrm{K}))$ for liquid PCM, solid PCM, test tube and water, respectively; $A$ is the area enclosed by $T$ - $t$ curve and the ambient temperature curve $\left(\mathrm{m}^{2}\right) ; A^{\prime}$ is the area encircled by the reference water curve and the ambient temperature curve $\left(\mathrm{m}^{2}\right)$; subscripts 1,2 and 3 represent stage 1 , stage 2 and stage 3 , respectively.

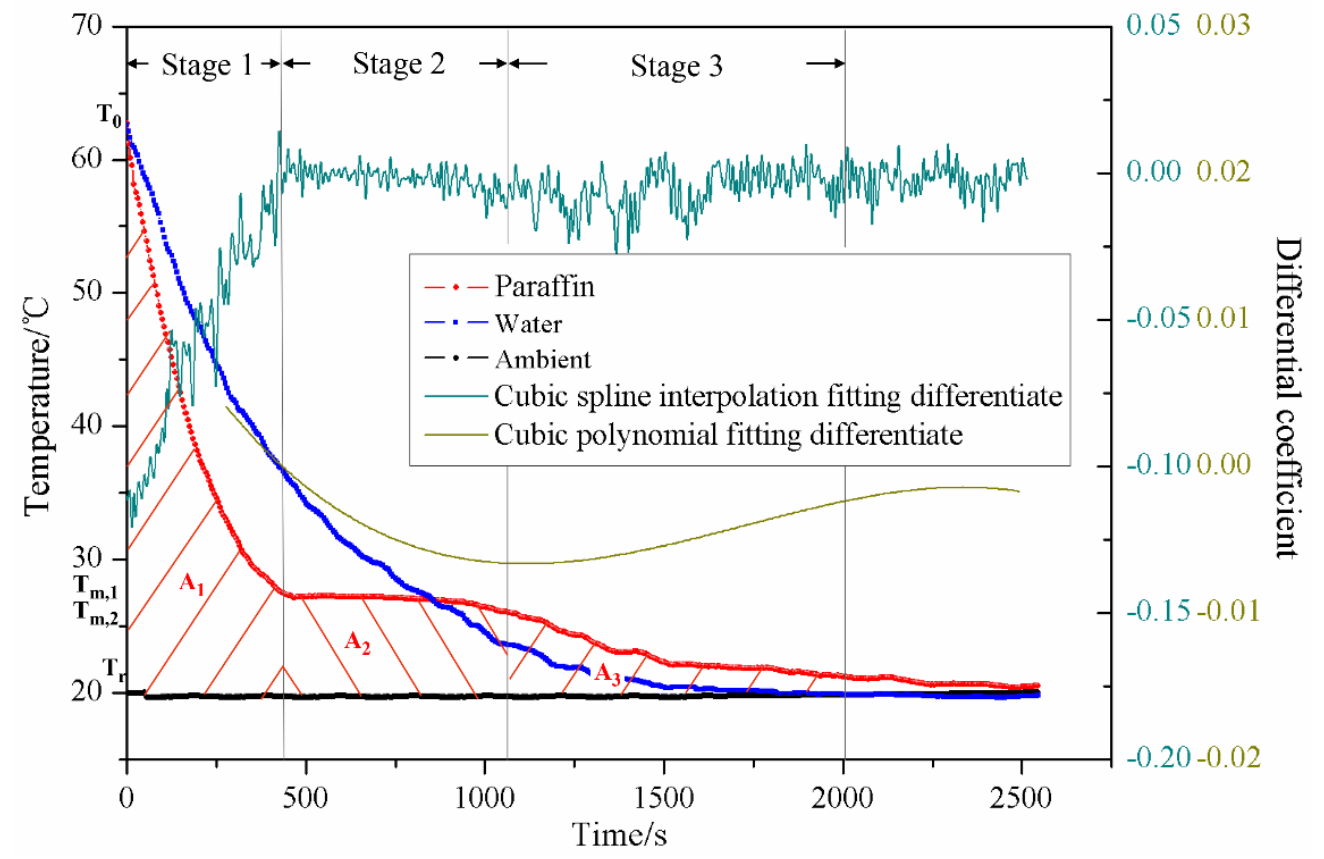

Fig. 4. Determination of $T_{m, 1}$ and $T_{m, 2}$ using T-history curve

By solving Eqs. (2)-(6) the specific heat of solid PCM and liquid PCM, and the latent heat can be obtained by Eqs. (7), (8) and (9), respectively.

$$
\begin{gathered}
c_{p, s}=\left(\frac{m_{w} c_{p, w}+m_{t} c_{p, t}}{m_{p}}\right) \times\left(\frac{A_{3}}{A_{2}^{\prime}}\right)-\frac{m_{t}}{m_{p}} c_{p, t} \\
c_{p, l}=\left(\frac{m_{w} c_{p, w}+m_{t} c_{p, t}}{m_{p}}\right) \times\left(\frac{A_{1}}{A_{1}^{\prime}}\right)-\frac{m_{t}}{m_{p}} c_{p, t} \\
H_{m}=\left(\frac{m_{w} c_{p, w}+m_{t} c_{p, t}}{m_{p}}\right) \times\left(\frac{A_{2}}{A_{1}^{\prime}}\right) \times\left(T_{0}-T_{m, 1}\right)-\frac{m_{t} c_{p, t}\left(T_{m, 1}-T_{m, 2}\right)}{m_{p}}
\end{gathered}
$$


Apparently, the key step to solve the above mentioned thermophysical parameters (specific heat and latent heat) is to determine $T_{m, 1}$ and $T_{m, 2}$. No supercooling phenomenon was observed in solidification prococess of paraffin and the temperature tended to descend continuously in the period of phase change. The method proposed by Zhang and Jiang [23] to determine $T_{m, 1}$ and $T_{m, 2}$ mainly aimed at the PCM with a large supercooling degree. In this paper, the methods from Ref. [24] and Refs. [25, 2626] were adopted to determine $T_{m, 1}$ and $T_{m, 2}$ respectively. Considering the slope changes of $T-t$ curve, which had a marked decline at $T_{m, 1}$, then flattened and then significantly declined at $T_{m, 2}$, the differential value abruptly changing (inflection points) was adopted as the beginning and end point of phase change period $\left(T_{m, 1}\right.$ and $\left.T_{m, 2}\right)$ respectively. The experimental data were fitted by a cubic spline interpolation and the first derivative of the fitting curve was obtained. The vertical coordinate of the peak of the first derivative curve was $T_{m, 1}$. The cubic polynomial method was then used in fitting the data from phase change to natural cooling stage. The first derivative of the fitting curve was solved and the vertical coordinate of the lowest point of the first derivative curve was marked as $T_{m, 2}$.

The thermal conductivity $(k)$ of PCMs can be obtained from Eq. (10) with the experimental data from the T-history method [27].

$$
k=\frac{\rho H_{m} R_{m}{ }^{2}}{4 t_{f}\left(T_{m}-T_{\infty}\right)}
$$

where $R_{m}$ is the radius of phase transition zone and $t_{f}$ is the phase change time of PCMs.

The heat storage and heat release characteristics of composite PCMs during melting and solidification were tested in thermostatic water bath systems with temperatures of $50{ }^{\circ} \mathrm{C}$ and $10{ }^{\circ} \mathrm{C}$, respectively. The temperatures acquisition interval was $5 \mathrm{~s}$.

\subsubsection{Error Analysis}

In the original T-history method, only latent heat change was considered during phase transition, meaning that a single phase change temperature of PCM was assumed. However, the actual phase change temperatures of paraffin-based composite PCM were not on a horizontal line in the T-t curve. PCM also releases sensible heat due to temperature fluctuation during phase transition. This part of sensible heat has an effect on heat capacity during phase change. The generated calculation error of $H_{m}$ due to the neglect of sensible heat between $T_{m, 1}$ and $T_{m, 2}$, was defined in Eq. (11). 


$$
\delta=\frac{c_{p, s}+c_{p, l}}{2}\left(T_{m, 1}-T_{m, 2}\right)
$$

As shown in Fig. $4, T_{m, 1}$ of the tested n-octadecane was $28.2{ }^{\circ} \mathrm{C}$ and $T_{m, 2}$ was $26.1^{\circ} \mathrm{C}$. The latent heat $H_{m}$ was $239.41 \mathrm{~kJ} / \mathrm{kg}$ and the calculation error with Eq. (11) was $3.98 \mathrm{~kJ} / \mathrm{kg}$. Compared with the referenced latent heat value of n-octadecane of $243.5 \mathrm{~kJ} / \mathrm{kg}$, the deviation was $1.7 \%-3.3 \%$, which is acceptable. For the composite SSPCMs added with hybrid CNs, there are no theoretical standard values of latent heat. In this paper, the method of ref. [23] was adopted to make the error analysis.

The main thermo-physical properties in the current study, such as specific heat $c_{p}$, latent heat $H_{m}$, thermal conductivity $k$ were calculated from equations (7) - (10), their errors mainly come from the errors in measurements [23], and thus they can be analyzed by:

$$
\begin{gathered}
\frac{\Delta H_{m}}{H_{m}} \approx \frac{4 \Delta T}{T_{m}-T_{\infty}}+\frac{2 \Delta T}{T_{0}-T_{m}} \\
\frac{\Delta c_{p, s}}{c_{p, s}} \approx \frac{2 \Delta T}{T_{m}-T_{\infty}}+\frac{2 \Delta T}{T_{r}-T_{m}} \\
\frac{\Delta c_{p, l}}{c_{p, l}} \approx \frac{4 \Delta T}{T_{m}-T_{\infty}} \\
\frac{\Delta k}{k} \approx \frac{4 \Delta T}{T_{m}-T_{\infty}}+\frac{2 \Delta H_{m}}{H_{m}}
\end{gathered}
$$

The relative errors of the $c_{p}, H_{m}$, and $k$ of PCMs for errors in measurement of the temperature $\Delta T$ are listed in Table 4.

Table 4 Relative errors of measurements

\begin{tabular}{llll}
\hline$\Delta T\left({ }^{\circ} \mathrm{C}\right)$ & 0.5 & 0.1 & 0.01 \\
\hline$\Delta H_{m} / H_{m}(\%)$ & 30 & 6 & 0.6 \\
$\Delta c_{p, s} / c_{p, s}(\%)$ & 40 & 8 & 0.8 \\
$\Delta c_{p, l} / c_{p, l}(\%)$ & 30 & 6 & 0.6 \\
$\Delta k / k(\%)$ & 80 & 16 & 1.6 \\
\hline
\end{tabular}

\subsubsection{Comprehensive evaluation}

Comprehensive evaluation was applied to assess the overall performance of the composite PCMs and analyze the optimal mass ratio of the hybrid CNs in the composite PCMs. Seven key properties of the composite PCMs, which are the leakage rate $(L R)$, latent heat $\left(H_{m}\right)$, specific heat of both solid and liquid state $\left(c_{p, s}, c_{p, l}\right)$, thermal conductivity 
$(k)$, melting time (MT) and solidification time (ST), were applied to develop the comprehensive evaluation factor. Firstly, the satisfaction (upper limit) and dissatisfaction values (lower limit) were determined separately for each property, and then converted into the dimensionless indexes by linear correlation method. Then a comprehensive index, called the total efficacy coefficient, was obtained by weighted integration and used to assess the overall performance of the composite PCMs. In general, the greater the total efficacy coefficient is, the better the overall performance of the system is.

The satisfaction value $X_{h i}$ is the highest level and the unsatisfactory value $X_{s i}$ is the lowest level. The efficacy coefficient $d_{i}$ of each evaluation index can be classified into the positive effect index (the larger the better) and the negative effect index (the smaller the better), which can be calculated by Eq. (16) and Eq. (17).

$$
\begin{gathered}
d_{i, p o s i t i v e}=\left\{\begin{array}{c}
\frac{X_{i}-X_{s i}}{X_{h i}-X_{s i}} \times 0.4+0.6, X_{i} \leq X_{h i} \\
1, X_{i} \geq X_{h i}
\end{array}\right. \\
d_{i, \text { negative }}=\left\{\begin{array}{c}
\frac{X_{i}-X_{s i}}{X_{h i}-X_{s i}} \times 0.4+0.6, X_{i} \geq X_{h i} \\
1, X_{i} \leq X_{h i}
\end{array}\right.
\end{gathered}
$$

The weighting determination of ECM is an objective method, in which the mean value $\bar{X}_{i}$ and the standard deviation $\sigma_{i}$ of the evaluation index $i$ were calculated in advance, and the weight factor $\omega_{i}$ of the index was calculated from the Eqs. (18-19).

$$
\begin{gathered}
v_{i}=\sigma_{i} / \overline{X_{i}} \\
\omega_{i}=v_{i} / \sum_{1}^{n} v_{i}
\end{gathered}
$$

The total efficacy coefficient $D_{i}$ of each SSPCM sample was calculated by Eq. (20).

$$
D_{i}=\prod_{1}^{n} d_{i}^{\omega_{i}}
$$

\section{Results and discussion}

\subsection{Leakage rate}

The relationships between the leakage rates of five n-octadecane-HDPE SSPCMs and time are plotted in Fig. 5. The seepage photos of all the samples on the filter paper for seven consecutive hours of heating in the vacuum drying oven (at $50{ }^{\circ} \mathrm{C}$ ) are also shown in Fig. 5. After an hour, evident seepage of S1 S5 was found and the leakage rates of 
S1 S5 were $20.37 \%, 6.85 \%, 5.89 \%, 5.28 \%$ and $3.09 \%$, respectively. The leakage was mainly due to the surface residual paraffin during the melt blending process [28]. After four hours, the leakage rate curves were stabilized for all the samples. After seven hours, the total leakage rate of S1 was $44.92 \%$, indicating that $17 \mathrm{wt} . \%$ of HDPE can no longer play a shape-stabilization role. The total leakage rates of S2 S5 were $11.66 \%, 10.77 \%$, $10.07 \%$ and $8.22 \%$ respectively, indicating that the sample with more HDPE was able to achieve better shape stabilization effect. However, the latent heat reduced with more HDPE added as shown in Table 1. In this case, the optimal mass fraction of HDPE should be considered based on both shape stabilization ability and latent heat. Considering porous EG can also possibly detain the liquid paraffin, the minimal mass fraction of $20 \mathrm{wt} . \%$ HDPE suggested in the published literature was chosen in the studied n-octadecaneHDPE composites with hybrid CNs: EG-MWCNT and EG-CNF.
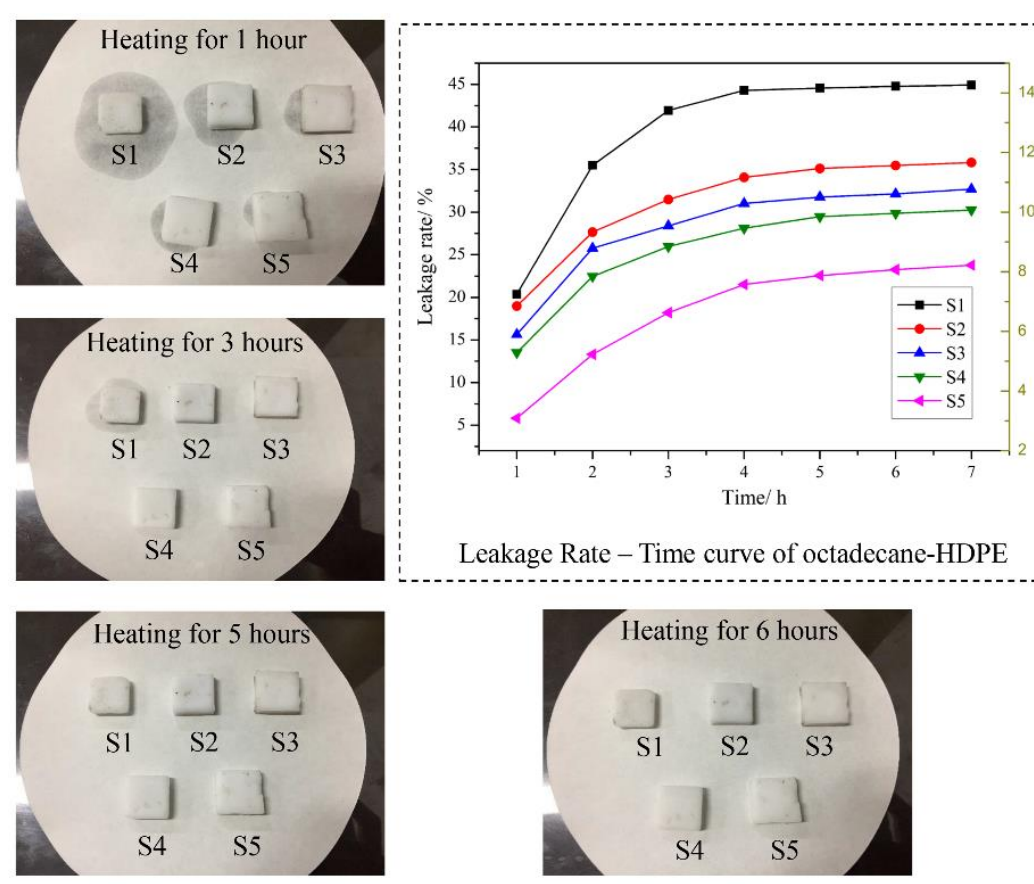

Leakage Rate - Time curve of octadecane-HDPE
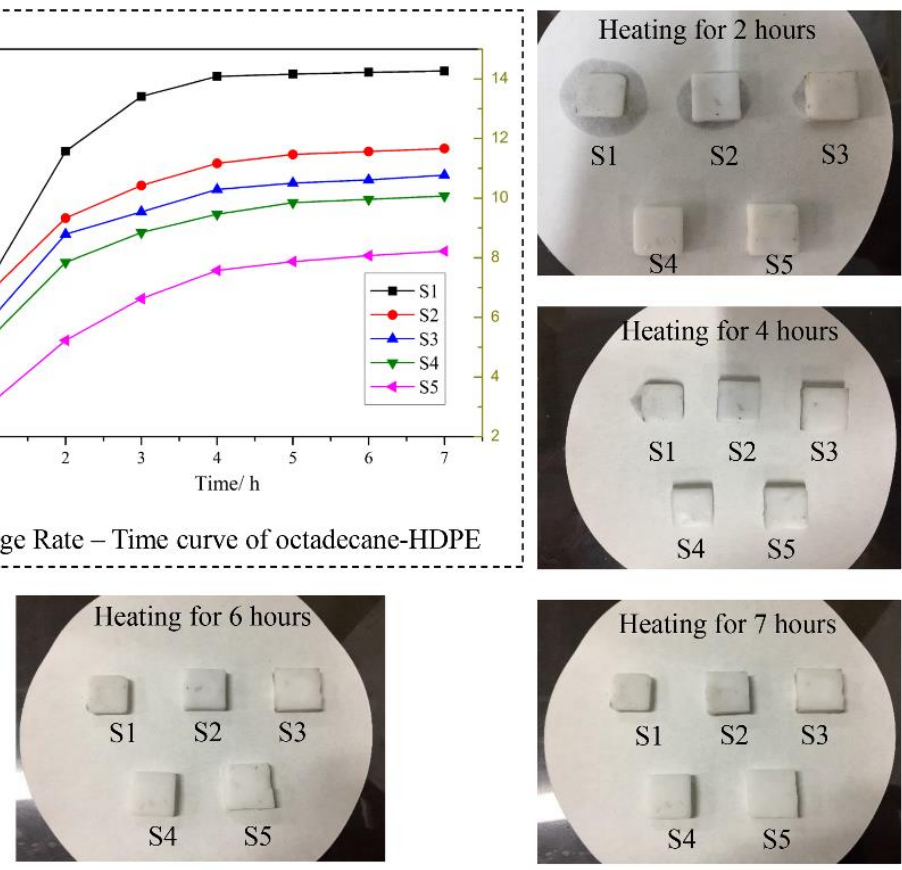

Fig. 5 Leakage rate and photos of n-octadecane-HDPE SSPCM composites in thermal cycling experiment

The relationships between the leakage rates and time of the n-octadecane-HDPE/EGMWCNT and n-octadecane-HDPE/EG-CNF composite PCMs are presented in Fig. 6. The leakage rates of M1 M5 and C1 C5 increased significantly during the first three hours of the thermal cycling, due to the residual melting on the surface of the samples. After four hours, the leakage rate curves of all the samples were almost unchanged. After seven hours, the total leakage rates of M1 M5 reached 8.28\%, 9.31\%, 9.83\%, 10.22\%, 
10.35\% (shown in Fig. 6(a)), and the total leakage rates of $\mathrm{C} 1 \sim \mathrm{C} 5$ reached $8.28 \%, 9.05 \%$, 9.17\%, 9.89\%, 10.90\% (shown in Fig. 6(b)). The addition of CNs can help support the shape stabilization of the samples. The leakage rate decreased with the increase of EG. However, MWCNT and CNF did not work better on shape support compared with EG, shown in Fig. 6. The reason is that the porous structure of EG can adsorb more liquid paraffin. The CNF worked slightly better than MWCNT as the samples with the same proportion of CNF had a slightly lower leakage rate than those with MWCNT.

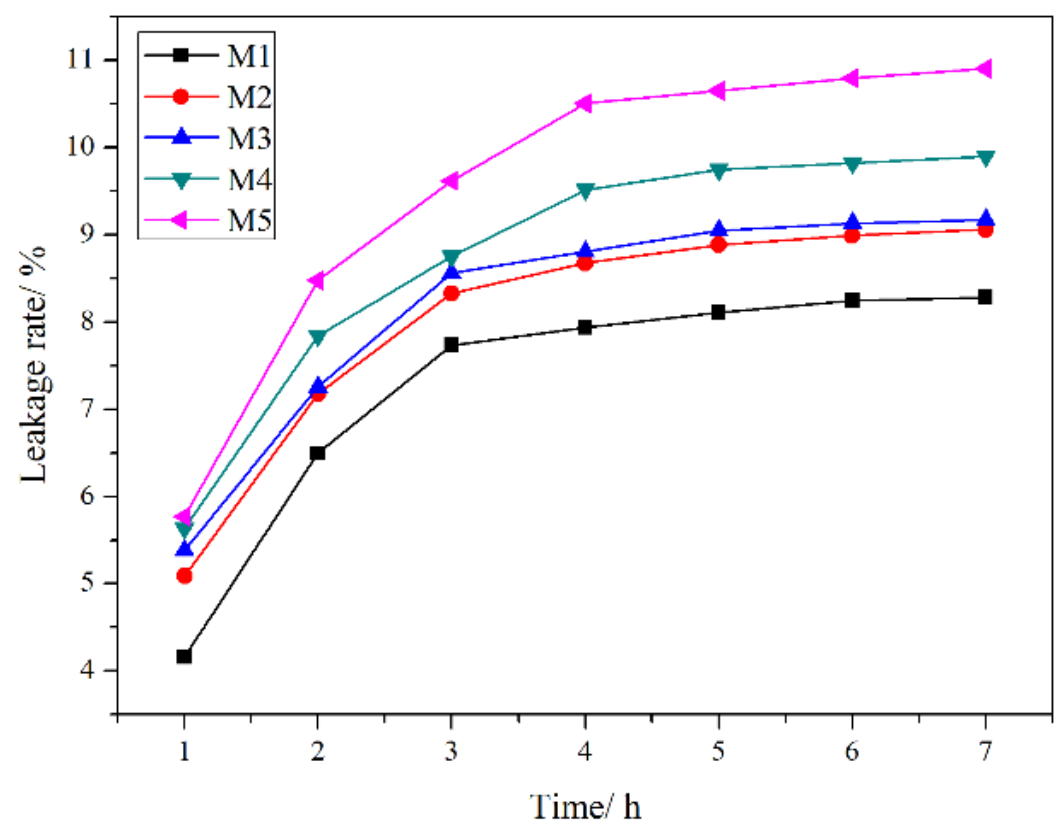

(a) n-octadecane-HDPE/EG-MWCNT

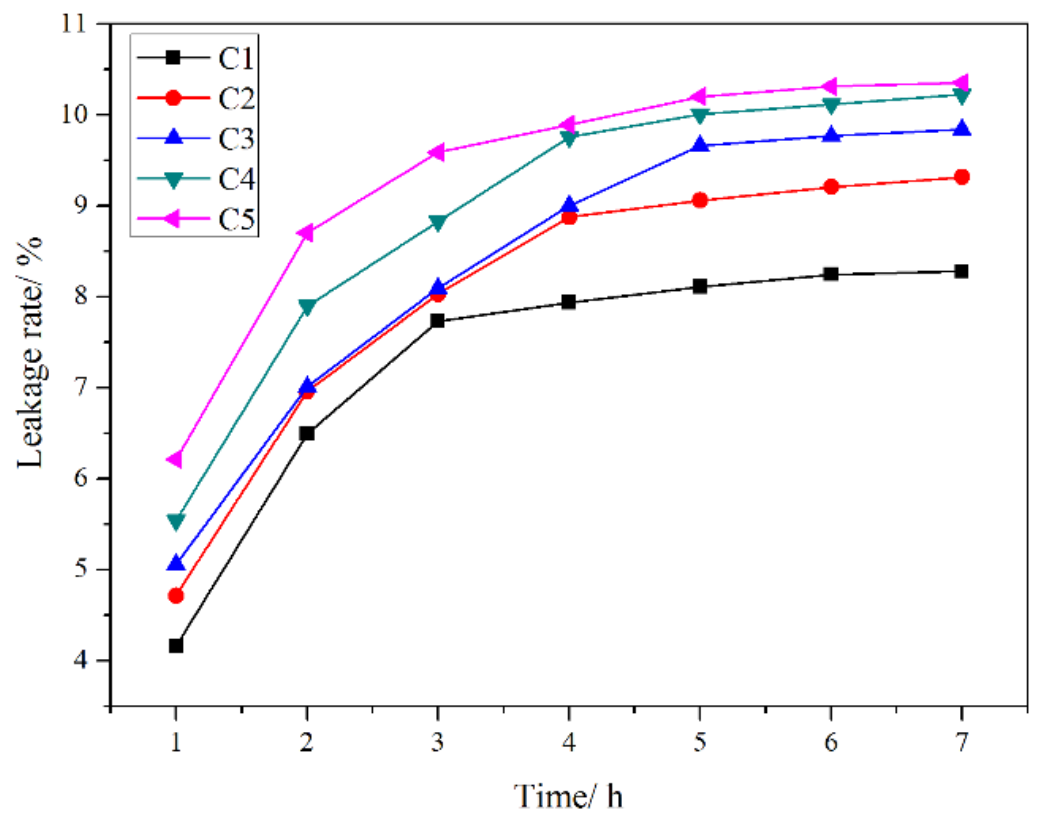

(b) n-octadecane -HDPE/EG-CNF

Fig. 6 Leakage rate-time curves of the studied SSPCM composites with hybrid CNs 
fillers

\subsection{T-t curve}

Fig. 7 (a) and (b) are the T-history curves of n-octadecane-HDPE/EG-MWCNT and noctadecane-HDPE/EG-CNF, respectively. The composite SSPCMs showed a slight supercooling phenomenon. S2 showed a maximum supercooling degree of $0.5^{\circ} \mathrm{C}$. The possible reason is that after adding HDPE, the crystallization mode of paraffin is changed, and a slight supercooling is needed to trigger the solidification. For other composite SSPCMs, the supercooling degrees of M4 and M5 were $0.4{ }^{\circ} \mathrm{C}$, higher than M3 $\left(0.3{ }^{\circ} \mathrm{C}\right)$, M2 $\left(0.1^{\circ} \mathrm{C}\right)$ and $\mathrm{M} 1\left(0.1^{\circ} \mathrm{C}\right)$. The supercooling degree of $\mathrm{C} 2$ was $0.4^{\circ} \mathrm{C}$, higher than $\mathrm{C} 3$ $\left(0.3{ }^{\circ} \mathrm{C}\right), \mathrm{C} 4\left(0.3{ }^{\circ} \mathrm{C}\right), \mathrm{C} 5\left(0.2{ }^{\circ} \mathrm{C}\right)$ and $\mathrm{C} 1\left(0.1^{\circ} \mathrm{C}\right)$.

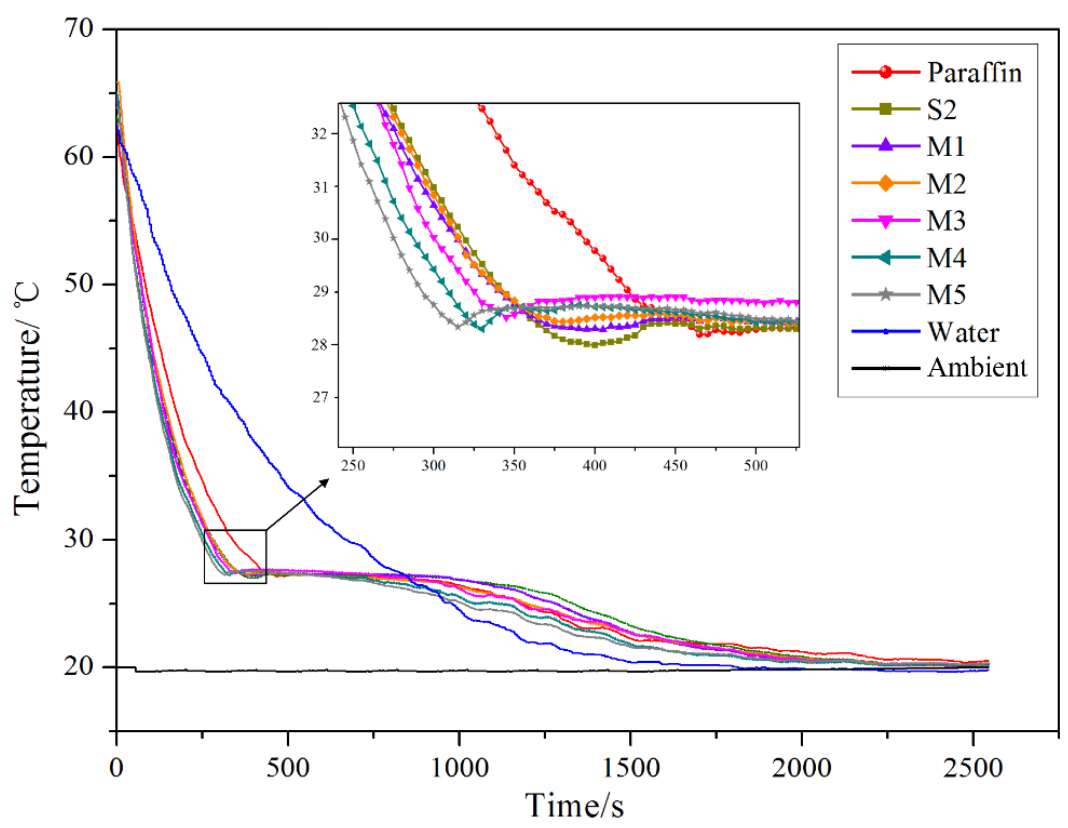

(a) n-octadecane-HDPE/EG-MWCNT 


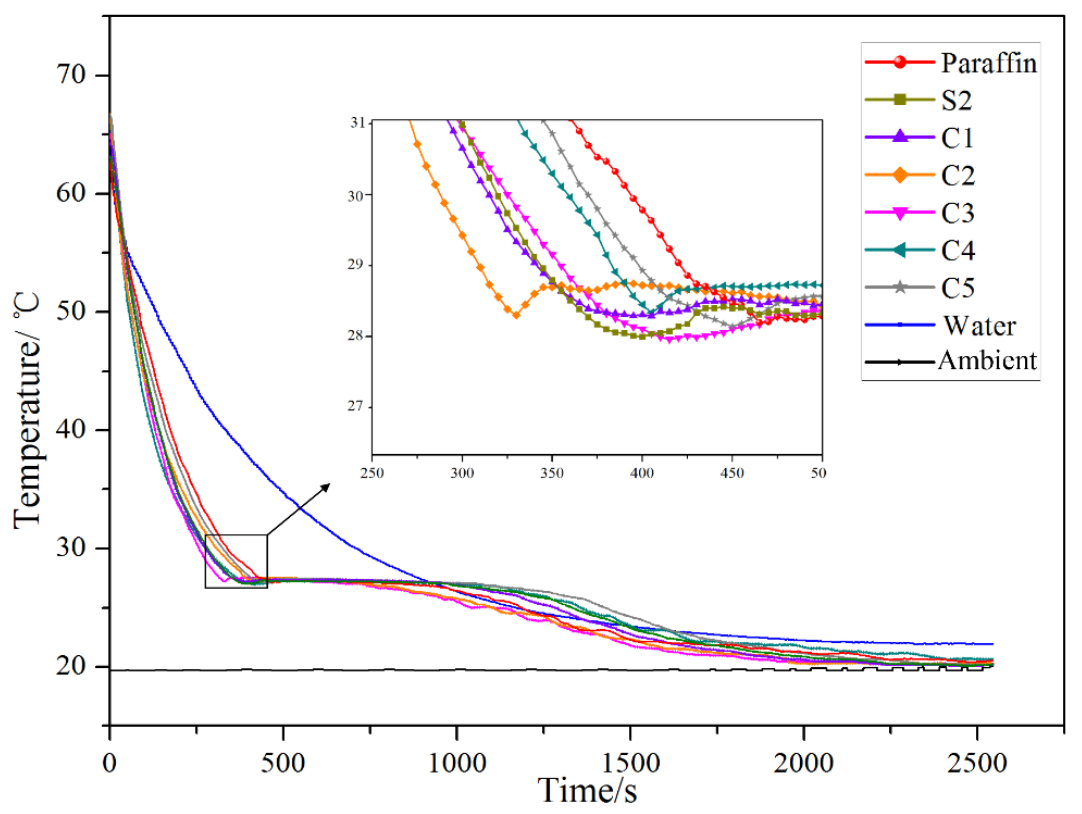

(b) n-octadecane-HDPE/EG-CNF

Fig. 7 T-history curves of the studied SSPCM composites with hybrid CNs fillers

The temperature recovery rate, which is the time for reaching the phase change temperature after supercooling, is a representation of the thermal diffusivity of the sample. A faster temperature recovery rate indicates a higher thermal diffusivity. As shown in Fig. 7, the n-octadecane-HDPE/EG-MWCNT and n-octadecane-HDPE/EG-CNF composite PCMs had higher thermal conductivity coefficient than S2 (n-octadecane-HDPE SSPCM). It also displayed that the thermal diffusivity of M4 and M5 was roughly the same, but higher than that of M1, M2 and M3. Similarly, the thermal diffusivity of C4 and C5 was roughly the same, but higher than that of $\mathrm{C} 1, \mathrm{C} 2$ and $\mathrm{C} 3$. This phenomenon is related to the content of EG. The increase rate in the thermal diffusivity of the composite was inversely affected by the increase of EG content. The possible reason is that the combination of EG and HDPE strengthens the shaping of n-octadecane but restricts the natural convection of the liquid phase.

Both n-octadecane-HDPE/EG-MWCNT and n-octadecane-HDPE/EG-CNF composites showed the same tendency in the relationship between thermal diffusivity and mass ratio of CNs, which is EG: MWCNT or EG: $\mathrm{CNF}=4: 1>3: 2>5: 0>1: 1>0: 5$. The phase change temperature fluctuations between $T_{m, 1}$ and $T_{m, 2}$ for $\mathrm{S} 2, \mathrm{M} 1 \sim \mathrm{M} 5$ and $\mathrm{C} 1 \sim \mathrm{C} 5$ were $1.9^{\circ} \mathrm{C}, 1.6^{\circ} \mathrm{C}, 1.5^{\circ} \mathrm{C}, 1.2^{\circ} \mathrm{C}, 1.4^{\circ} \mathrm{C}, 1.4{ }^{\circ} \mathrm{C}, 1.6{ }^{\circ} \mathrm{C}, 1.7{ }^{\circ} \mathrm{C}, 2 .{ }^{\circ} \mathrm{C}, 1.7{ }^{\circ} \mathrm{C}$ and $1.9{ }^{\circ} \mathrm{C}$, respectively. 


\subsection{Thermo-physical properties}

Table 5 lists the calculated values of seven key thermal parameters of the studied SSPCM composites by T-history method. The starting and finishing phase change temperatures of paraffin and all the SSPCM composites only showed very limited differences, with a maximum difference of $0.9^{\circ} \mathrm{C}$ and $1.6^{\circ} \mathrm{C}$, respectively. The variation of the phase change temperature did not have a particular relationship with the mass ratio of EG-MWCNT or EG-CNF. The reason might be the addition of HDPE and CNs changed the arrangement of paraffin molecules and induced the randomness of local steric hindrance changes, which caused a slight change in the phase change temperature.

The experimental values of specific heat of solid n-octadecane is higher than its real value. The reason is that the calculated $A_{2}^{\prime}$ is smaller because $T_{m 2}$ was used in instead of the phase change temperature in Eq. (6) and $T_{m 2}$ is smaller than it. The difference between $T_{m 2}$ and $T_{w}$ was about $0.5^{\circ} \mathrm{C}$ and thereby $c_{p, s}$ of n-octadecane was overrated by $35 \%$. The specific heat of solid composite PCM was larger than that of melt composite PCM, and the maximum difference among the specific heat of solid PCM samples $(0.15$ $\mathrm{kJ} /(\mathrm{kg} \cdot \mathrm{K}))$ was less than that of liquid PCM samples $(0.32 \mathrm{~kJ} /(\mathrm{kg} \cdot \mathrm{K}))$. The relationship between the mass ratios of PCM composites and specific heat was irregular, and the difference was less than $12.5 \%$. The similar conclusions were found in the study of EGCNT SSPCM by Liu et al. [21]. In general, the additives incorporation (HDPE and hybrid CNs) increased the specific capacity of the composite PCM. As known, the specific heat of PCMs changes according to their surrounding temperature, the specific heat is the larger the better to serve as buffers for sudden and/or severe changes in thermal conditions to greater extent. Therefore, the results that HDPE and CNs showed positive effect on specific heat of PCM composites were well expected.

Table 5 Calculated thermophysical properties of the PCM composites

\begin{tabular}{lllllllll}
\hline Samples & $\begin{array}{l}T_{m, 1} \\
\left({ }^{\circ} \mathrm{C}\right)\end{array}$ & $\begin{array}{l}T_{m, 2} \\
\left({ }^{\circ} \mathrm{C}\right)\end{array}$ & $\begin{array}{l}c_{p, s} \\
(\mathrm{~kJ}\end{array}$ & $\begin{array}{l}c_{p, l} \\
(\mathrm{~kJ} \cdot \mathrm{K}))\end{array}$ & $\begin{array}{l}H_{m} \\
(\mathrm{~kg} \cdot \mathrm{K}))\end{array}$ & $\begin{array}{l}\delta \\
(\mathrm{kJ} / \mathrm{kg})\end{array}$ & $\begin{array}{l}H_{m} \text { ratio }^{1} \\
(\mathrm{~kJ} / \mathrm{kg})\end{array}$ & $\begin{array}{l}k \\
(\mathrm{~W} /(\mathrm{m} \cdot\end{array}$ \\
\hline n-octadecane & 28.2 & 26.8 & 3.28 & 2.54 & 239.4 & 3.98 & 100 & 0.25 \\
S2 & 28.8 & 26.9 & 3.31 & 2.42 & 189.0 & 5.22 & 78.4 & 0.28 \\
M1 & 28.2 & 26.6 & 3.42 & 2.29 & 171.1 & 4.59 & 71.1 & 0.85 \\
M2 & 29.1 & 27.6 & 3.43 & 2.26 & 170.5 & 4.20 & 70.8 & 1.36 \\
M3 & 28.6 & 27.4 & 3.31 & 2.23 & 168.3 & 3.26 & 69.9 & 1.09 \\
M4 & 28.3 & 26.9 & 3.38 & 2.30 & 168.8 & 3.88 & 70.1 & 0.71 \\
M5 & 29.0 & 27.6 & 3.34 & 2.22 & 170.2 & 4.01 & 70.7 & 0.52 \\
C1 & 28.2 & 26.6 & 3.42 & 2.29 & 171.1 & 4.59 & 71.1 & 0.85 \\
C2 & 28.2 & 26.5 & 3.39 & 2.32 & 168.4 & 4.68 & 69.9 & 1.03
\end{tabular}




\begin{tabular}{lllllllll} 
C3 & 28.3 & 26.0 & 3.30 & 2.29 & 166.3 & 5.44 & 69.1 & 0.96 \\
C4 & 28.3 & 26.6 & 3.31 & 2.23 & 167.3 & 4.89 & 69.5 & 0.54 \\
C5 & 28.3 & 26.4 & 3.28 & 2.27 & 169.4 & 5.30 & 70.3 & 0.37 \\
\hline
\end{tabular}

${ }^{1}$ the latent heat of samples / paraffin

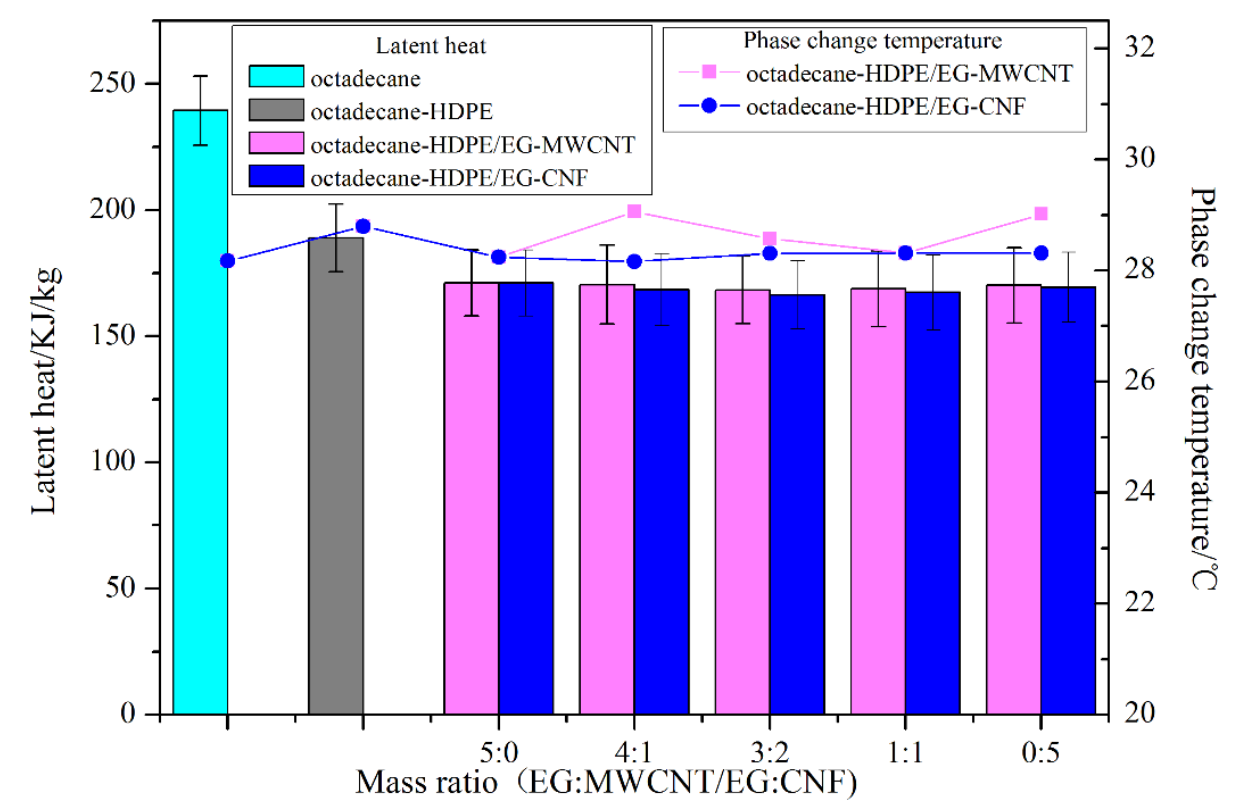

Fig. 8 Comparison of phase change temperature and latent heat among SSPCM composites

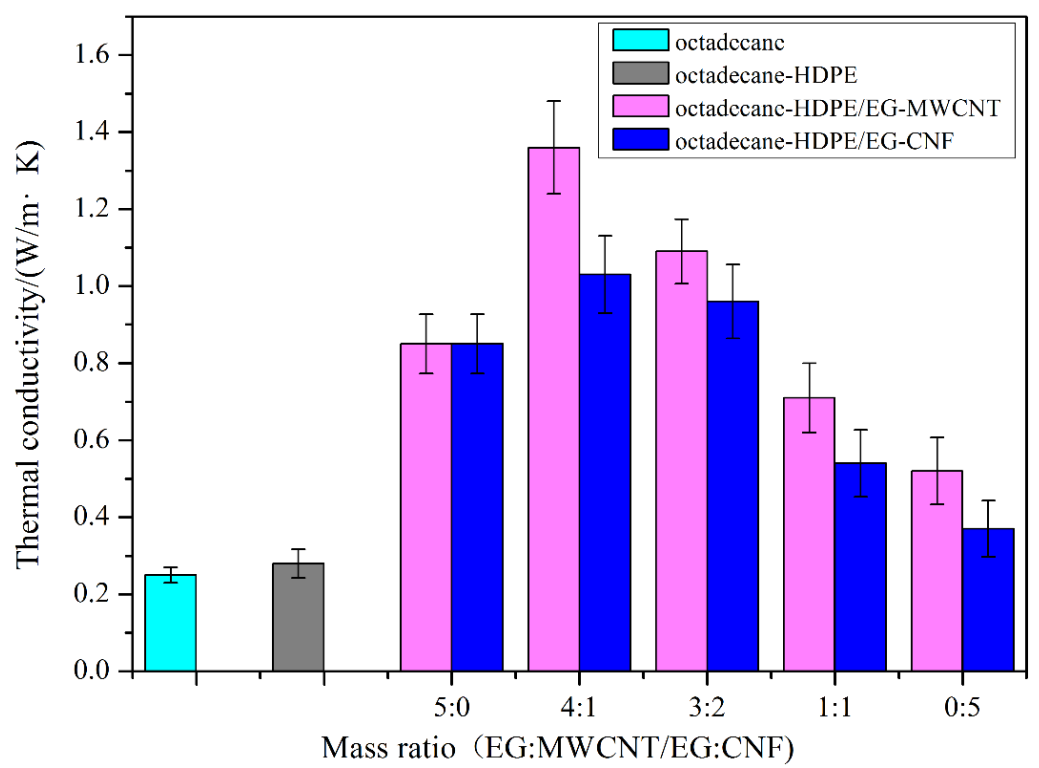

Fig. 9 Comparison of thermal conductivity among SSPCM composites

The latent heat decreased a little bit due to the addition of the CNs. Fig. 8 shows the effects of mass ratios of different $\mathrm{CNs}$ on the phase change temperature and latent heat of SSPCM composites. Paraffin had the maximum latent heat of $239.41 \mathrm{~kJ} / \mathrm{kg}$. The latent heat of S2 was reduced to $188.98 \mathrm{~kJ} / \mathrm{kg}$ with addition of $20 \mathrm{wt}$ \% HDPE, with a reduced rate of $21 \%$. Under the same loading of $5 \mathrm{wt} . \%$ thermal conductive fillers, the latent heat 
of Paraffin-HDPE/EG-MWCNT was between 168.27 and $171.1 \mathrm{~kJ} / \mathrm{kg}$, with reduced rates of $8 \sim 9 \%$ of S2. The latent heat of Paraffin-HDPE/EG-CNF composites was in the range of $166.34 \sim 171.1 \mathrm{~kJ} / \mathrm{kg}$ with reduced rates of $9 \sim 10 \%$ of S2. The latent heat values of two composite PCMs have little difference no matter the kind and mass ratio of the two hybrid CNs. For example, the maximum variation of latent heat for Paraffin-HDPE/EGMWCNT was only $2.83 \mathrm{~kJ} / \mathrm{kg}$ between M1 and M3 while $4.76 \mathrm{~kJ} / \mathrm{kg}$ for ParaffinHDPE/EG-CNF between $\mathrm{C} 1$ and $\mathrm{C} 3$. The $H_{m}$ ratios were positively correlated with the mass ratio of n-octadecane in the sample, indicating that the latent heat of the composite PCMs was mainly proportional to the mass fraction of n-octadecane. At the same mass fraction, the addition of hybrid thermal conductive fillers weakens the latent heat a little more than the single thermal conductive filler.

Fig. 9 shows the relationship between the thermal conductivity of SSPCM composites and the mass ratio of two kinds of hybrid CNs. HDPE showed no observable effect on the thermal conductivity of paraffin because the thermal conductivity of S2 with the addition of $20 \mathrm{wt} . \%$ HDPE was almost the same as that of pure paraffin. Comparing the two types of SSPCM composites, the mass ratios of EG-MWCNT and EG-CNF had the same effect rule on the thermal conductivity enhancement, with EG-MWCNT-based PCM composites showing better thermal conductivities than EG-CNF-based PCM composites due to the higher thermal conductivity of MWCNT than CNF. Both EGMWCNT-based and EG-CNF-based PCM composites showed the best synergistic thermal enhancement effect at the mass ratio of $4: 1$, increased by $60 \%$ and $21.2 \%$ respectively compared to the case with only $5 \mathrm{wt} . \%$ EG. The mass ratio (4:1) of EG and other CN enhancer (MWCNT or CNF) was proved to be able to establish a more effective heat conduction pathway, promoting heat transfer more quickly and effectively through the whole PCM composite.

\subsection{Heat storage and release rate}

The melting and solidification of SSPCM composites are unsteady processes and the heat transfer are constantly changing, therefore, it is necessary to investigate how addition of hybrid $\mathrm{CN}$ fillers works on the heat storage and heat release rate. Both melting and solidification process roughly undergo three stages. Fig. 10 (a) and (b) are the melting curves of Paraffin-HDPE/EG-MWCNT and Paraffin-HDPE/EG-CNF. The first stage from $10{ }^{\circ} \mathrm{C}$ to phase change temperature of $27^{\circ} \mathrm{C} \sim 29^{\circ} \mathrm{C}$ was sensible heat storage in 
solid phase, in which the heat transfer process was dominated by heat conduction. In this stage, the addition of hybrid CN fillers increased the heat storage rate. Paraffin and S2 took $525 \mathrm{~s}$ and $530 \mathrm{~s}$ from the initial temperature to phase change temperature, respectively. M1 M5 reduced the time by $31.4 \%, 51.4 \%, 40 \%, 19 \%$ and $10.5 \%$ compared to pure paraffin and $\mathrm{C} 1 \sim \mathrm{C} 5$ reduced the time by $29 \%, 49.5 \%, 39.3 \%, 21.3 \%$ and $8.5 \%$. The second stage was the phase transition, in which the temperature only changed a little with a co-existence of the solid and liquid phases in PCM. The third stage was the sensible heat storage. Paraffin and S2 took $675 \mathrm{~s}$ and $1805 \mathrm{~s}$ from the finish of phase change to $50{ }^{\circ} \mathrm{C}$. M1 M5 decreased the time by $34 \%, 55.3 \%, 44.7 \%, 14.9 \%$ and $10.6 \%$ compared to $\mathrm{S} 2$ and $\mathrm{C} 1 \sim \mathrm{C} 5$ decreased the time by $32.7 \%, 45.1 \%, 38.2 \%, 19.3 \%$ and $11.8 \%$. The increase of the heat storage rate followed the change trends of thermal conductivity enhancement. The reason is that the liquid PCM was bound in the porous framework formed by HDPE and the heat transfer process was dominated by heat conduction. From Fig. 10, the total melting time of M1 M5 and $\mathrm{C} 1 \sim \mathrm{C} 5$ were reduced by $32.5 \%, 54.6 \%$, $43.1 \%, 13.3 \%, 8.9 \%, 32.5 \%, 47.7 \%, 37 \%, 19.2 \%$ and $11.3 \%$ compared with S2 (2335 s). Therefore, M2 showed the fastest heat storage rate among all studied SSPCM composites.

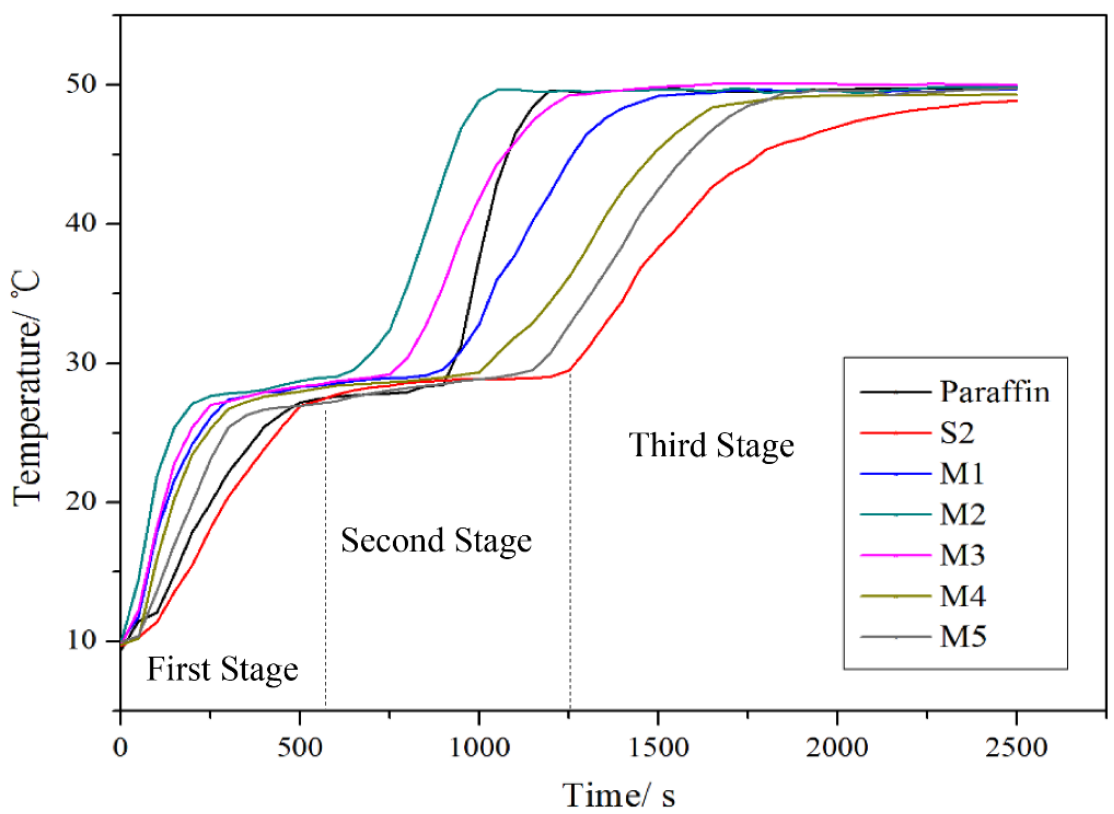

(a) n-octadecane-HDPE/EG-MWCNT 


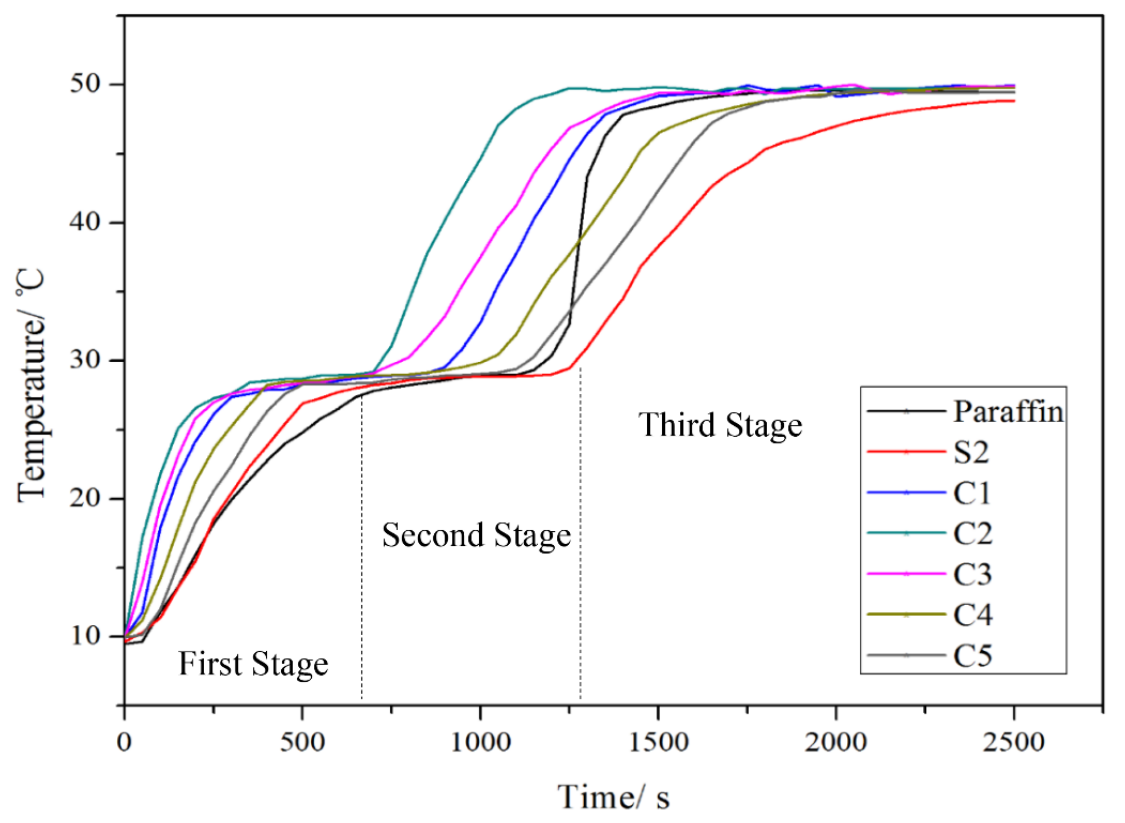

(b) n-octadecane-HDPE/EG-CNF

Fig. 10 Temperature-time curves of the SSPCM composites in the melting process

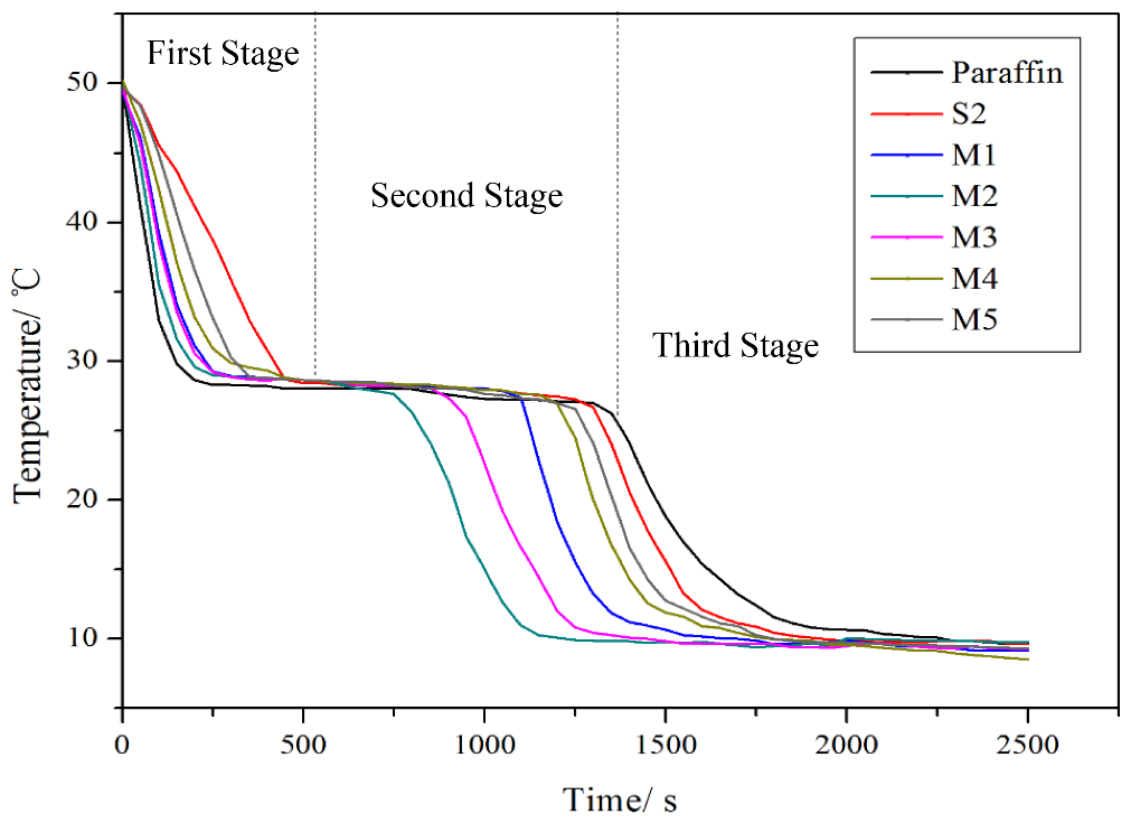

(a) n-octadecane-HDPE/EG-MWCNT 


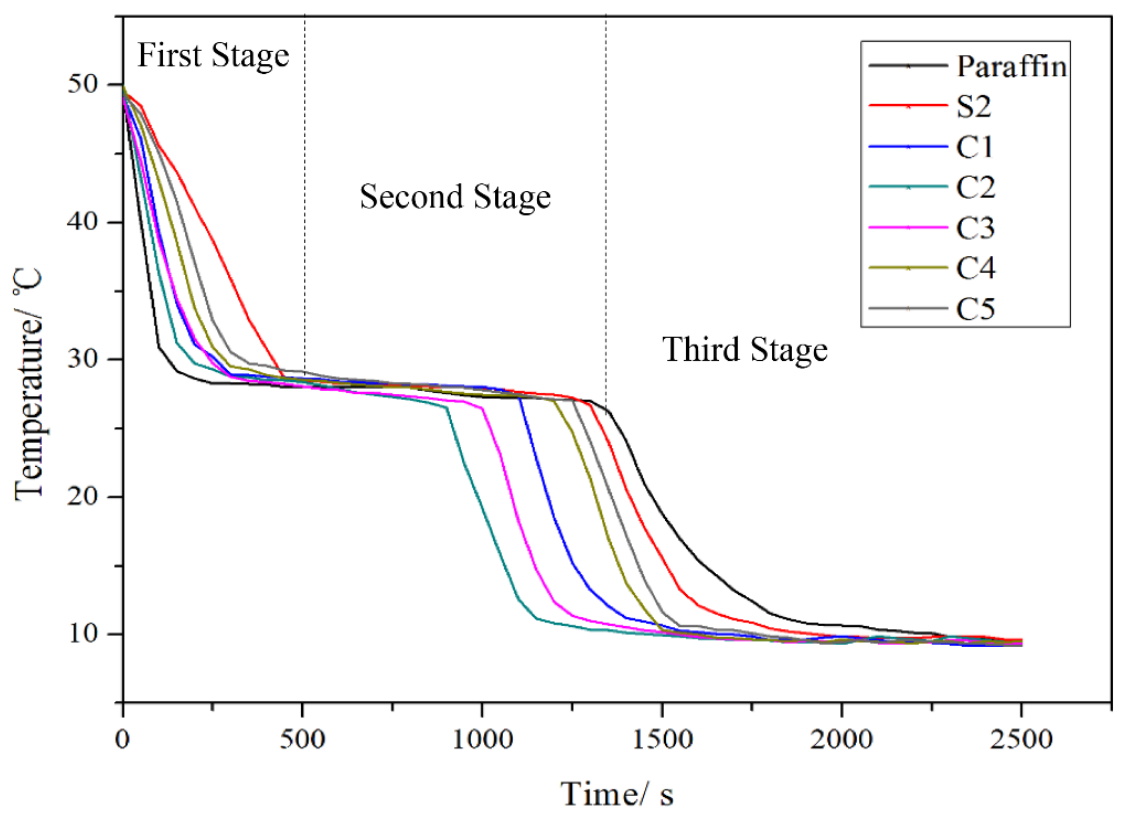

(b) n-octadecane-HDPE/EG-CNF

Fig. 11 Temperature-time curve of the SSPCM composites in the solidification process

Fig. 11 (a) and (b) are the solidification curves of n-octadecane-HDPE/EG-MWCNT and n-octadecane-HDPE/EG-CNF. Similar to the melting process, M2 had the fastest heat release rate. The total solidification time of $\mathrm{M} 1 \sim \mathrm{M} 5$ and $\mathrm{C} 1 \sim \mathrm{C} 5$ were reduced by by $23.4 \%, 42.7 \%, 33.6 \%, 30.9 \%, 15.5 \%, 23.4 \%, 29.1 \%, 26.1 \%, 13.6 \%$ and $8.9 \%$ compared with S2 (2200 s).

Adding thermal conductive fillers in paraffin can effectively increase heat storage and release rate. The increasing tendency of heat storage/release rates coincides with the enhancement of thermal conductivity. The optimal heat storage/release rates occurred when the mass ratio of EG: MWCNT was $4: 1$. The total melting and solidification time of n-octadecane-HDPE/EG-MWCNT and n-octadecane-HDPE/EG-CNF were shortened by $54.6 \%$ and $42.7 \%$ compared with S2.

\subsection{Comprehensive evaluation}

The comprehensive evaluation of performance of SSPCM composites was constructed, including seven indexes: leakage rate $(L R)$, latent heat $\left(H_{m}\right)$, specific heat of solid and liquid PCM $\left(c_{p, s}, c_{p, l}\right)$, thermal conductivity $(k)$, melting time (MT) and solidification time (ST).

Table 6 Evaluation indexes of the PCM composites

\begin{tabular}{|c|c|c|c|c|c|c|c|}
\hline Samples & $\begin{array}{l}L R \\
(\%)\end{array}$ & $\begin{array}{l}H_{m} \\
(\mathrm{~kJ} / \mathrm{kg})\end{array}$ & $\begin{array}{l}c_{p, s} \\
(\mathrm{~kJ} \\
/(\mathrm{kg} \cdot \mathrm{K}))\end{array}$ & $\begin{array}{l}c_{p, l} \\
(\mathrm{~kJ} \\
/(\mathrm{kg} \cdot \mathrm{K}))\end{array}$ & $\begin{array}{l}k \\
(\mathrm{~W} /(\mathrm{m} \cdot \mathrm{K}))\end{array}$ & $\begin{array}{l}\text { MT } \\
\text { (s) }\end{array}$ & $\begin{array}{l}\text { ST } \\
\text { (s) }\end{array}$ \\
\hline
\end{tabular}




\begin{tabular}{llllllll}
\cline { 1 - 3 } M1 & 8.28 & 171.10 & 3.42 & 2.29 & 0.85 & 1575 & 1685 \\
M2 & 9.32 & 170.45 & 3.43 & 2.26 & 1.36 & 1060 & 1260 \\
M3 & 9.84 & 168.27 & 3.31 & 2.23 & 1.09 & 1330 & 1460 \\
M4 & 10.22 & 168.79 & 3.38 & 2.30 & 0.71 & 2025 & 1520 \\
M5 & 10.35 & 170.16 & 3.34 & 2.22 & 0.52 & 2125 & 1860 \\
C1 & 8.28 & 171.10 & 3.42 & 2.29 & 0.85 & 1575 & 1685 \\
C2 & 9.06 & 168.37 & 3.39 & 2.32 & 1.03 & 1220 & 1560 \\
C3 & 9.17 & 166.34 & 3.30 & 2.29 & 0.96 & 1470 & 1625 \\
C4 & 9.90 & 167.29 & 3.31 & 2.23 & 0.54 & 1885 & 1900 \\
C5 & 10.90 & 169.38 & 3.28 & 2.27 & 0.37 & 2070 & 2005 \\
\hline
\end{tabular}

Table 6 summarized the test results of such indexes, in which $H_{m}, c_{p, s}, c_{p, l}$ and $k$ are positive effect indexes while the leakage rate $(L R)$, the melting time (MT), the solidification time (ST) are the negative effect indexes. Table 7 showed the satisfaction value $X_{h i}$ and the dissatisfaction value $X_{s i}$ for each index. The efficacy coefficient $d_{i}$ was calculated by Eqs. (16) and (17), shown in Table 8. Table 9 showed the mean value $\bar{X}_{i}$, the standard deviation $\sigma_{i}$, the coefficient of variation $v_{i}$ and the weighting factor $\omega_{i}$ calculated by Eqs. (18) and (19).

Table 7 Satisfaction values and dissatisfaction values of each evaluation index

\begin{tabular}{llllllll}
\hline $\begin{array}{l}\text { Parame } \\
\text { ters }\end{array}$ & $\begin{array}{l}L R \\
(\%)\end{array}$ & $\begin{array}{l}H_{m} \\
(\mathrm{~kJ} / \mathrm{kg})\end{array}$ & $\begin{array}{l}c_{p, s} \\
(\mathrm{~kJ} /(\mathrm{kg} \cdot \mathrm{K}))\end{array}$ & $\begin{array}{l}c_{p, l} \\
(\mathrm{~kJ} /(\mathrm{kg} \cdot \mathrm{K}))\end{array}$ & $\begin{array}{l}k \\
(\mathrm{~W} /(\mathrm{m} \cdot \mathrm{K}))\end{array}$ & $\begin{array}{l}\text { MT } \\
(\mathrm{s})\end{array}$ & $\begin{array}{l}\mathrm{ST} \\
(\mathrm{s})\end{array}$ \\
\hline$X_{h i}$ & 8.28 & 171.10 & 3.43 & 2.32 & 1.36 & 1060 & 1260 \\
$X_{s i}$ & 10.90 & 167.29 & 3.28 & 2.27 & 0.37 & 2125 & 2005 \\
\hline
\end{tabular}

Table 8 Effect coefficient $d i$ of each index of the PCM composites

\begin{tabular}{llllllll}
\hline Samples & $\begin{array}{l}L R \\
(\%)\end{array}$ & $\begin{array}{l}H_{m} \\
(\mathrm{~kJ} / \mathrm{kg})\end{array}$ & $\begin{array}{l}c_{p, s} \\
(\mathrm{~kJ} \\
/(\mathrm{kg} \cdot \mathrm{K}))\end{array}$ & $\begin{array}{l}c_{p, l} \\
(\mathrm{~kJ} \\
/(\mathrm{kg} \cdot \mathrm{K}))\end{array}$ & $\begin{array}{l}k \\
(\mathrm{~W} /(\mathrm{m} \cdot \mathrm{K}))\end{array}$ & $\begin{array}{l}\mathrm{MT} \\
(\mathrm{s})\end{array}$ & $\begin{array}{l}\mathrm{ST} \\
(\mathrm{s})\end{array}$ \\
\hline M1 & 1 & 1 & 0.97 & 0.76 & 0.79 & 0.81 & 0.77 \\
M2 & 0.84 & 0.93 & 1 & 0.52 & 1 & 1 & 1 \\
M3 & 0.76 & 0.70 & 0.68 & 0.28 & 0.89 & 0.90 & 0.89 \\
M4 & 0.70 & 0.76 & 0.87 & 0.84 & 0.74 & 0.64 & 0.86 \\
M5 & 0.68 & 0.90 & 0.76 & 0.2 & 0.66 & 0.6 & 0.68 \\
C1 & 1 & 1 & 0.97 & 0.76 & 0.79 & 0.81 & 0.77 \\
C2 & 0.88 & 0.71 & 0.89 & 1 & 0.87 & 0.94 & 0.84 \\
C3 & 0.86 & 0.50 & 0.65 & 0.76 & 0.83 & 0.85 & 0.80 \\
C4 & 0.75 & 0.6 & 0.68 & 0.28 & 0.67 & 0.69 & 0.66 \\
C5 & 0.6 & 0.82 & 0.6 & 0.6 & 0.6 & 0.62 & 0.6 \\
\hline
\end{tabular}

Table 9 Mean value, standard deviation, coefficient of variation and weighting factor of each evaluation index

\begin{tabular}{llllllll}
\hline Parameters & $\begin{array}{l}L R \\
(\%)\end{array}$ & $\begin{array}{l}H_{m} \\
(\mathrm{~kJ} / \mathrm{kg})\end{array}$ & $\begin{array}{l}c_{p, s} \\
(\mathrm{~kJ} /(\mathrm{kg} \cdot \mathrm{K}))\end{array}$ & $\begin{array}{l}c_{p, l} \\
(\mathrm{~kJ} /(\mathrm{kg} \cdot \mathrm{K}))\end{array}$ & $\begin{array}{l}k \\
(\mathrm{~W} /(\mathrm{m} \cdot \mathrm{K}))\end{array}$ & $\begin{array}{l}\mathrm{MT} \\
(\mathrm{s})\end{array}$ & $\begin{array}{l}\mathrm{ST} \\
(\mathrm{s})\end{array}$ \\
\hline$\overline{X_{i}}$ & 9.67 & 168.90 & 3.35 & 2.27 & 0.83 & 1640 & 1652.8 \\
$\sigma_{i}$ & 0.75 & 1.45 & 0.05 & 0.03 & 0.30 & 375.7 & 223.01 \\
$v_{i}$ & 0.08 & 0.01 & 0.02 & 0.01 & 0.36 & 0.23 & 0.13
\end{tabular}


Fig. 12 showed the total efficacy coefficient $D_{i}$ calculated by Eq. (20), from which it can be seen that the comprehensive performance of the n-octadecane-HDPE/EG-MWCNT was better than n-octadecane-HDPE/EG-CNF in general. Two SSPCM composites exhibited the same tendency of comprehensive performance with the mass ratio variation of the two thermal conductive fillers, which are EG: MWCNT or EG: $\mathrm{CNF}=4: 1>3: 2>5: 0>1: 1>0: 5$. The comprehensive performance of EG: MWCNT=4:1 was the best, followed by EG: $\mathrm{CNF}=4: 1$ and $\mathrm{EG}$ : $\mathrm{MWCNT}=3: 2$. With the same total loading of $5 \mathrm{wt} . \%$ thermal conductive fillers, these three samples above showed better comprehensive performance than the composite with only EG. It is proved that the addition of EG-MWCNT and EG-CNF can enhance the comprehensive performance of PCM composites.

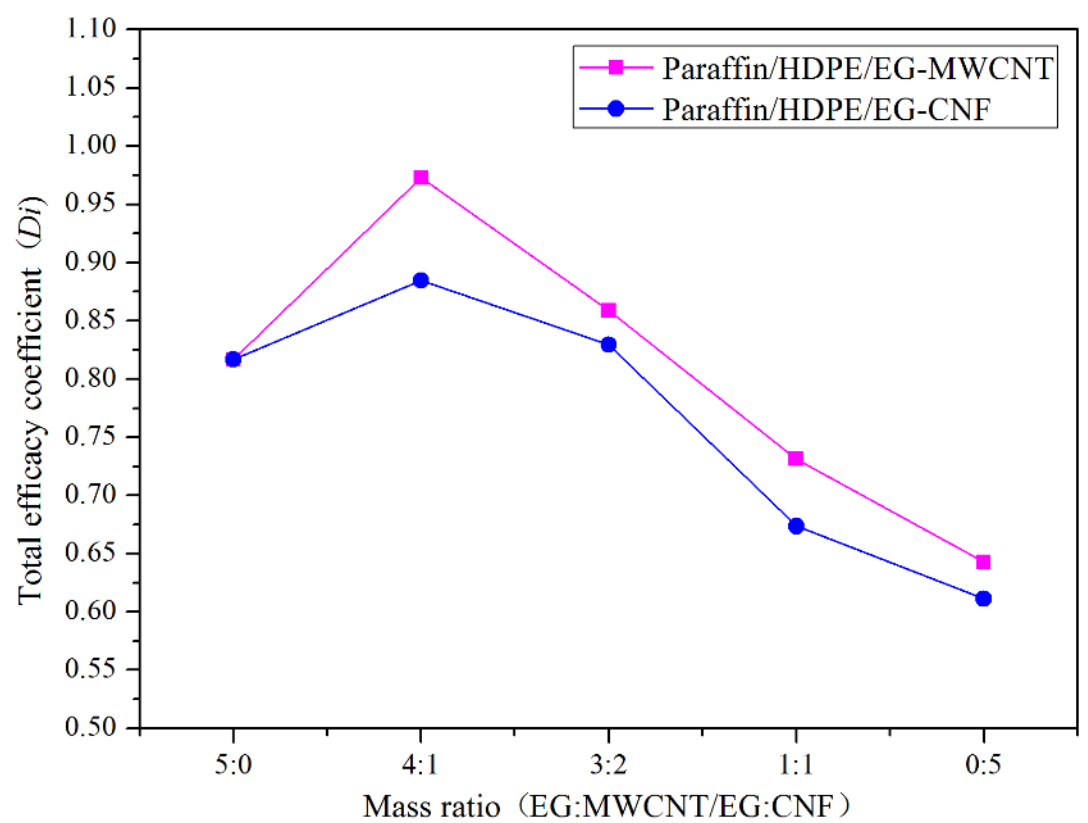

Fig. 12 Comparison of the total efficacy coefficient $D i$ of two PCM composites

\section{Conclusions}

Paraffin-HDPE based SSPCMs with two kinds of hybrid CNs additives, EG-MWCNT and EG-CNF, were manufactured by melt blending method. The total mass fraction of the additives was 5wt.\% and different mass ratios of EG-MWCNT or EG-CNF were studied. The addition of CNs additives had only a slight effect on the phase change temperature compared with pure PCM (n-octadecane). It can also give further support for the shape stabilization and thermal stability. In general, the addition of EG-CNF worked slightly better than EG-MWCNT for the SSPCM composites with same mass ratio of EG and the 
other $\mathrm{CN}$ additive.

Efficacy Coefficient Method (ECM) was firstly introduced in this paper to comprehensively evaluate the performance of SSPCM composites and determine the optimal mass ratio of EG and the other $\mathrm{CN}$ additive from an overall aspect. Seven indexes were calculated based on experimental results, including leakage rate, specific heat of liquid and solid phase, latent heat, thermal conductivity, heat storage and release time and then they were integrated into the total efficacy coefficient of each SSPCM composite. The results showed that the n-octadecane-HDPE/EG-MWCNT with the mass ratio of EG and MWCNT of 4:1 exhibited the best comprehensive performance among all the tested SSPCM composites. Addition of thermal conductive fillers or shape supporter into the PCM can affect its thermal properties. This comprehensive method can give an evaluation on the overall performance of the composites.

\section{Acknowledgments}

This work is supported by the Natural Science Foundation of Shandong Province in China (No.ZR201702120003), the Fundamental Research Funds for the Central Universities (19CX02043A), the National Natural Science Foundation of China (No.51206189), State Key Laboratory of Heavy Oil Processing, De Montfort University through its distinguished Vice-Chancellor 2020 Programme, and the UK Science and Technology Facilities Council (STFC) through Batteries Early Career Researcher Award. The authors greatly appreciate their financial support.

\section{Reference}

[1] W.L. Cheng, R.M. Zhang, K. Xie, N. Liu, J. Wang. Heat conduction enhanced shapestabilized paraffin/HDPE composite PCMs by graphite addition: Preparation and thermal properties. Solar Energy Materials and Solar Cells 94 (10) (2010) 1636-1642.

[2] C. Amaral, R. Vicente, P. Marques, A. Barros-Timmons. Phase change materials and carbon nanostructures for thermal energy storage: A literature review. Renewable \& Sustainable Energy Reviews 79 (2017) 1212-1228.

[3] A. Castell, C. Solé, M. Medrano, J. Roca, L.F. Cabeza, D. Carcía. Natural convection heat transfer coefficients in phase change material (PCM) modules with external vertical fins. Applied Thermal Engineering 28(13) (2008) 1676-1686.

[4] S.G. Krishnan, E Vinayak. Numerical investigation of thermal performance of PCM based heat sink using structured porous media as thermal conductivity enhancers. International Journal of Thermal Sciences 104 (2016) 266-280.

[5] L.W. Fan, X. Fang, X. Wang, Y. Zeng, Y.Q. Xiao, Z.T. Yu, X. Xu, Y.C. Hu, K.F. Cen. 
Effects of various carbon nanofillers on the thermal conductivity and energy storage properties of paraffin-based nanocomposite phase change materials. Applied Energy 110 (5) (2013) 163-172.

[6] A. Elgafy, K. Lafdi. Effect of carbon nanofiber additives on thermal behavior of phase change materials. Carbon 43 (15) (2005) 3067-3074.

[7] S. Shaikh, K. Lafdi, K. Hallinan. Carbon nanoadditives to enhance latent energy storage of phase change materials. Journal of Applied Physics 103 (2008) 094302.

[8] X. Huang, Y.X. Lin, G. Alva, G.Y. Fang. Thermal properties and thermal conductivity enhancement of composite phase change materials using myristyl alcohol/metal foam for solar thermal storage. Solar Energy Materials and Solar Cells 170 (2017) 68-76.

[9] X. Xiao, P.G. Zhang, M. Li. Effective thermal conductivity of open-cell metal foams impregnated with pure paraffin for latent heat storage. International Journal of Thermal Sciences 81 (1) (2014) 94-105.

[10] Y. Qu, S. Wang, D. Zhou, Y. Tian. Experimental study on thermal conductivity of paraffin-based shape-stabilized phase change material with hybrid carbon nanoadditives. Renewable Energy 146 (2020) 2637-2645.

[11] H.B. Kim, M. Mae, Y. Choi, T. Kiyota. Experimental analysis of thermal performance in buildings with shape-stabilized phase change materials. Energy and Buildings 152 (2017) 524-533.

[12] N. Zhu, S.S. Li, P.F. Hu, S. Wei, R.J. Deng, F. Lei. A review on applications of shapestabilized phase change materials embedded in building enclosure in recent ten years. Sustainable Cities and Society 43 (2018) 251-264.

[13] D. Zhou, P.C. Eames. Phase Change Material Wallboard (PCMW) melting temperature optimization for passive indoor temperature control. Renewable Energy 193 (2019) 507-514.

[14] H. Inaba, P. Tu. Evaluation of thermophysical characteristics on shape-stabilized paraffin as a solid-liquid phase change material. Heat and Mass Transfer 32 (4) (1977) 307-312.

[15] Y.P. Zhang, K.P. Lin, R. Yang, H.F. Di, Y. Jiang. Preparation, thermal performance and application of shape-stabilized PCM in energy efficient buildings. Energy and Buildings 38 (10) (2006) 1262-1269.

[16] P.H. Qin, R. Yang, Y.P. Zhang, K.P. Lin. Thermal properties of shape stabilized phase change materials. Journal of Tsinghua University (Natural Science Edition) 43 (6) (2003) 833-835. (in Chinese)

[17] A. Sarı. Form-stable paraffin/high density polyethylene composites as solid-liquid phase change material for thermal energy storage: preparation and thermal properties. Energy Conversion and Management 45 (13) (2004) 2033-2042.

[18] K. Kaygusuz, A. Sar1. High density polyethylene/paraffin composites as form-stable phase change material for thermal energy storage. Energy Sources 29 (3) (2007) 261270.

[19] H. Ye, X.S. Ge. Preparation of polyethylene-paraffin compound as a form-stable solid-liquid phase change material. Solar Energy Materials and Solar Cells 64 (1) (2000) 37-44.

[20] B.Q. Tian, W.B. Yang, L.J. Luo. Synergistic enhancement of thermal conductivity for expanded graphite and carbon fiber in paraffin/EVA form-stable phase change materials. Solar Energy 127 (2016) 48-55.

[21] Z.P. Liu, R. Yang. Synergistically-Enhanced Thermal Conductivity of ShapeStabilized Phase Change Materials by Expanded Graphite and Carbon Nanotube. Applied Sciences 7 (6) (2017) 574.

[22] Y.C. Wang, H.W. Jing, L.J. Han, L.Y. Yu, Q. Zhang. Risk analysis on swell-shrink 
capacity of expansive soils with efficacy coefficient method and entropy coefficient method. Applied Clay Science 99 (9) (2014) 275-281.

[23] Y.P. Zhang, Y. Jiang. A simple method, the-history method, of determining the heat of fusion, specific heat and thermal conductivity of phase-change materials. Measurement Science and Technology 10 (3) (1999) 201.

[24] Y. Li, J. Qian, L.B. Wu. An improved method for calculating latent heat of material transformation based on T-history curve. Packaging engineering 23 (2014) 17-22. (in Chinese)

[25] H. Hong, C.H. Park, J.H. Choi. Improvement of the T-history method to measure heat of fusion for phase change materials. International Journal of Air-Conditioning and Refrigeration 11 (1) (2003) 32-39.

[26] H. Hong, S.K. Kim, Y.S. Kim. Accuracy improvement of T-history method for measuring heat of fusion of various materials. International Journal of Refrigeration 27 (4) (2004) 360-366.

[27] Y.P. Zhang. Phase change energy storage: theory and application. Press of China University of Science and Technology, 1996.

[28] J.A. Molefi, A.S. Luyt, I. Krupa. Comparison of LDPE, LLDPE and HDPE as matrices for phase change materials based on a soft Fischer-Tropsch paraffin wax. Thermochimica Acta 500 (1-2) (2010) 88-92. 